Sharif University of Technology
Scientia Iranica
Transactions E: Industrial Engineering
hCIENTIA

\title{
Optimal lot size in a manufacturing system with imperfect raw materials and defective finished products
}

\author{
H. Mokhtari* \\ Department of Industrial Engineering, Faculty of Engineering, University of Kashan, Kashan, P.O. Box 8731753153, Iran.
}

Received 14 December 2017; received in revised form 10 April 2018; accepted 5 May 2018

KEYWORDS
Manufacturing
systems;
Manufacturing
planning;
Imperfect raw
material;
Defective finished
product;
Reworking process.

\section{KEYWORDS}

uring

Manufacturing

planning;

Imperfect raw

material;

product;

Reworking process.

\begin{abstract}
In real-world manufacturing systems, it is inevitable to encounter imperfect raw materials and generate defective finished products. In order to cope with these practical problems, this paper studies a manufacturer that orders raw materials from an external source (supplier) and, then, produces a finished product. The raw materials contain imperfect quality items; in addition, the production system is defective. The imperfect raw materials are sold after the screening process, while the defective finished products go under a further rework process. It is also assumed that the defective rate of a machine is a random variable, resulting in three possible cases regarding the occurrence of backordering shortage. The aim is to determine economic order/production lot sizes for each case in such a way that the total cost of the system is minimized. The optimal closed-form solution is derived for each case separately. Moreover, the applicability of the proposed manufacturing model is illustrated via a numerical example.
\end{abstract}

(C) 2019 Sharif University of Technology. All rights reserved.

\section{Introduction}

One of the basic and useful production-inventory planning models is the Economic Order Quantity (EOQ). The aim of EOQ is to find economic lot size of materials to order from external sources so as to minimize the total cost of a system composed of holding and ordering costs. The classic EOQ was customized for manufacturing settings through economic production/manufacturing quantity (EPQ/EMQ) models. The traditional models of EOQ/EPQ are based on some simple assumptions such as:

(i) Demand rate for an item is pre-known and constant;

\footnotetext{
*. Tel.: +9803155912476

E-mail address: mokhtari_ie@kashanu.ac.ir
}

doi: $10.24200 /$ sci. 2018.50013 .1464 (ii) All order quantities are received instantaneouslyfor EOQ and, gradually, for EPQ;

(iii) Items are entirely consumed when the next order is received;

(iv) Shortage is not permitted and no safety stock is allowed;

((v) There is no quantity discount;

(vi) Ordering/setup cost is fixed per order/production;

(vii) All parameters are deterministic;

(viii) All received/produced items are of perfect quality.

Since holding and ordering costs behave inversely in basic EOQ/EPQ models, the total cost function is convex and, then, an intermediate amount of lot size is optimal. Based on the above assumptions, closed-form lot sizing can be simply calculated for the basic EOQ/EPQ 
models. The above assumptions are far from real conditions to justify the use of basic EOQ/EPQ models in practice. Therefore, a large body of literature has been allocated to relaxing these assumptions.

One of the assumptions in the manufacturing planning models, such as EPQ which is unrealistic, is that all items (raw materials received from external sources and finished products by own manufacturer) are of perfect quality and conform to all required characteristics perfectly. However, in reality, this assumption is not necessarily true and is a crucial weakness of traditional manufacturing models. For this reason, the problem of imperfect quality items has received the attention of researchers during recent years. Porteus [1] analyzed production lines in the out-of-control state when products are of imperfect quality and the rate of defective items is dependent on lot size. Moreover, Rosenblatt and Lee [2] studied the EPQ model with an imperfect process. Salameh and Jaber [3] did a great improvement in imperfect quality context by proposing an EOQ model considering a $100 \%$ inspection process upon receiving the products to identify defective products. The research of Salameh and Jaber [3] was modified by CárdenasBarrón [4] and Maddah and Jaber [5]. Rezaei [6] developed an inventory model with imperfect quality of items and fully backordered shortage. In addition, Yu et al. [7] extended the inventory model, which is imperfect with mixed partial backordering shortage and lost sales. Then, Wee et al. [8] studied the EPQ model with an imperfect quality alongside the rate of deterioration and partial backordering shortage. In addition, Papachristos and Konstantaras [9] proposed an inventory model with a constraint to avoid shortages. Moreover, Wee et al. [10] proposed an inventory model with fully backordering shortage. Khan et al. [11] presented a review of imperfect quality inventory models. At the same time, Wahab et al. [12] derived a coordinated level supply with shortages and environmental effects considering imperfect quality of items. Afterward, Konstantaras et al. [13] studied the impact of learning effect on the number of imperfect products and lot size. Liu and Zheng [14] suggested a fuzzy model with inspection errors in imperfect products. Moreover, Hsu and Hsu [15] proposed a general model for imperfect products with inspection errors, backordering shortage, and sales returns. In addition, Rad et al. [16] derived a price-dependent demand model for an integrated supply chain with an imperfect process and allowed shortage. Skouri et al. [17] developed an EOQ inventory model with imperfect products in the received lot and rejection of imperfect items to a supplier. In another work, Paul et al. [18] presented a joint replenishment problem to determine the lot size for products with defective items. Hlioui et al. [19] investigated a supply chain model with defective items with $100 \%$ screening. Sharifi et al. [20] studied the effect of inspection errors on inventory models with imperfect items and partial backordering shortage. Alamri et al. [21] evaluated the impact of learning on the inventory model with imperfect items. Chang et al. [22] developed an extension to the inventory model with imperfect items considering permissible delays in payments and inspection errors. Rezaei [23] proposed using sample inspection instead of full inspection in inventory models with imperfect items. Yu and Hsu [24] proposed an unequal sized shipment for a production-inventory problem with $100 \%$ inspection and item return. Sarkar and Saren [25] investigated warranty cost through the EPQ model considering defective items along with inspection error. Ongkunaruk et al. [26] proposed considering some constraints, such as shipment, budget, and transportation capacity constraints, in an inventory model with defective items. Taleizadeh et al. [27] proposed an imperfect EPQ manufacturing model with backordering allowed and trade credits. Cheikhrouhou et al. [28] proposed joint optimization of sample size and order size considering lot inspection policy and the withdrawing of defective batches. Taleizadeh and Zamani Dehkordi [29] considered an economic order quantity model with partial backordering and sampling inspection. Mokhtari and Rezvan [30] discussed a production-inventory system under VMI condition and partial backordering. Jaber et al. [31] extended the work of Salameh and Jaber [3] by proposing economic order quantity models considering imperfect items and buy and repair options when encountering a distant supplier. In addition to the above literature, a new direction of researches appears that considers randomness in the production system of the EPQ model. Chiu et al. [32] extended the economic production quantity model with nonconforming items for a case with random machine breakdown. Bouslah et al. [33] proposed joint lot sizing and production policy in an unreliable manufacturing system with random failure and repair. Mokhtari et al. [34] proposed the economic production quantity model for perishable products with stock-dependent demand and shortage backordered. Moreover, Tayyab and Sarkar [35] proposed a multi-stage production system with a random defective rate. Mokhtari [36] suggested a joint decision problem consisting of internal production replenishment and lotsizing optimization with supplier selection, considering defective manufacturing and rework option.

This paper proposes a production-inventory model where a manufacturer orders raw materials from an external source (supplier) and produces a finished product via a finite production rate. The raw materials contain imperfect quality items; hence, a 100\% screening process is implemented on lot-size receipt. On the other hand, the production system is also defective, 
and a fraction of finished products is imperfect. The imperfect raw materials are sold after the screening process, while the defective finished products go under a further rework process on the same machine. A number of defective products are reworkable and have the potential to become perfect after the reworking process, while others are scrapped items and sold at a lower price. It is also assumed that the defective rate of a machine is a random variable, resulting in three possible cases regarding the occurrence of backordering shortage. Here, two scenarios for each case are designed, resulting in six total states. The aim is to determine economic order/production lot sizes for each case in order to minimize the total cost of the system.

The rest of this paper is structured as follows. Section 2 presents the overall description of the problem and introduces the proposed manufacturing models via three possible cases. Then, Section 3 discusses numerical experiments. Finally, Section 4 presents conclusions.

\section{Manufacturing system modeling}

\subsection{Overall description and notations}

A new manufacturing model is proposed based on which a manufacturer produces a product to satisfy an external demand, $D$. The demand is assumed to be constant over a time horizon. The manufacturer produces the product via a finite production rate, $P_{1}$, under EPQ setting. In addition, the shortage is not allowed and purchase cost is fixed. In contrast to the standard models, it is assumed that the production system is defective and produces a percentage of imperfect items, $\beta$. The imperfect items are also under a rework process to become perfect and return to the consumption cycle. In general, an inventory cycle is composed of production, reworking, and depletion periods. After a production period, a percentage of defective items, $\beta$, which are reworkable, go under the rework process with rework rate, $P_{2}$. In real-world situations, many environmental features affect the production system and cause a fluctuation in the quality of produced items. Hence, as a realistic assumption, it is considered that the percentage of defective items, $\beta$, is a random variable. At the end of the rework period, the stored inventory is consumed until reaching zero during the depletion period. The production is carried out via production rate, $P_{1}$, within production period, $t_{p}$. Once the production ends, there exist imperfect items, $\beta Q$. Among them, the reworkable items, $\alpha \beta Q$, go under the reworking process, and the scrapped items, $(1-\alpha) \beta Q$, are disposed from the system. During the rework period $t_{R}$, all the reworkable items, $\alpha \beta Q$, become perfect with the rate of $P_{2}$ and return to the system. At the end of the rework period, the stored inventory is consumed during depletion period, $t_{D}$, until reaching zero. The next cycles repeat this process continuously. The aim is to determine optimal/economic production quantity, $Q$, such that the total profit is maximized. The total profit per cycle, $T P$, is obtained as the total revenue per cycle $T R$ minus the total cost per cycle, $T C$.

Herein, three possible cases (I, II, III) regarding the occurrence of shortage in the proposed system are analyzed. In Case I, shortage does not occur; therefore, the initial condition is considered as $I_{\max }-\beta Q \geq 0$. Since $I_{\max }=Q\left(1-D / P_{1}\right)$, this condition is simplified to:

$$
0 \leq \beta \leq 1-\frac{D}{P_{1}}
$$

In Case II, shortage occurs, yet is backordered fully. In this case, a shortage is encountered due to (1$\left.D / P_{1}\right)-\beta<0$; however, it is backordered because the number of reworked items minus demand during the rework period is greater than that of shortage, i.e., $\left(1-D / P_{1}\right)-\beta+\alpha \beta\left(1-D / P_{2}\right)>0$. These conditions are summarized as follows:

$$
1-\frac{D}{P_{1}}<\beta<\frac{1-D / P_{1}}{1-\alpha\left(1-D / P_{2}\right)} .
$$

Finally, in Case III, not only shortage occurs, but also the number of reworked items is not sufficient to cover all shortages occurred. In this case, there will be an amount of unsatisfied demand. To prevent lost sale, a special order is used at the end of the rework period (will be discussed later). The condition for this case is as follows:

$$
\frac{1-D / P_{1}}{1-\alpha\left(1-D / P_{2}\right)} \leq \beta \leq 1 .
$$

A famous condition in an EPQ model is that production rate $P$ should be greater than demand rate, $D$, in the classic EPQ model $(P>D)$. This condition ensures model feasibility and prevents severe shortage in all planning horizons. Conditions I-III play such a role in our model and should be checked before starting to solve the problem. Of course, the expected value of defective items should be considered in these constraints, since it is a random variable.

Before formulating the problem, the notations used throughout the paper are summarized as follows:

$\begin{array}{ll}D & \text { The demand rate of finished products; } \\ P_{1} & \text { The production rate of finished } \\ & \text { products; } \\ P_{2} & \text { The rework rate of finished products; } \\ A_{1} & \text { The fixed order cost of raw materials; }\end{array}$


$A_{2} \quad$ The fixed setup cost of finished products;

$h_{1} \quad$ The holding cost of raw materials per item per unit time;

$h_{2} \quad$ The holding cost of finished products per item per unit time;

$C_{1} \quad$ The purchase cost of raw materials per item;

$C_{2} \quad$ The production cost of finished products per item;

$d_{1} \quad$ The screening cost of raw materials per item;

$d_{2} \quad$ The screening cost of finished products per item; per item;

The selling price of imperfect raw materials per item;

The selling price of perfect finished products per item;

The selling price of scrapped finished products per item;

The screening rate of raw materials; The defective rate of finished products; The reworkable rate of defective finished products;

The imperfect rate of raw materials; The duration of screening period of raw materials;

The duration of the production period of finished products;

The duration of the rework period of finished products;

The duration of the depletion period of finished products;

[.] The expected value of random variable; The production quantity of finished products;

$b \quad$ The backorder quantity of finished products.

\subsection{Case I: When shortage does not occur}

Figure 1 shows one cycle of the proposed manufacturing system in Case I. To encounter the complexity of modeling a procedure gradually, two scenarios of this case in the sequel are considered. In the first scenario, the finished product cycle is only considered, while the raw material cycle is not considered. However, in the second scenario, both raw materials and finished product cycles are considered, simultaneously.

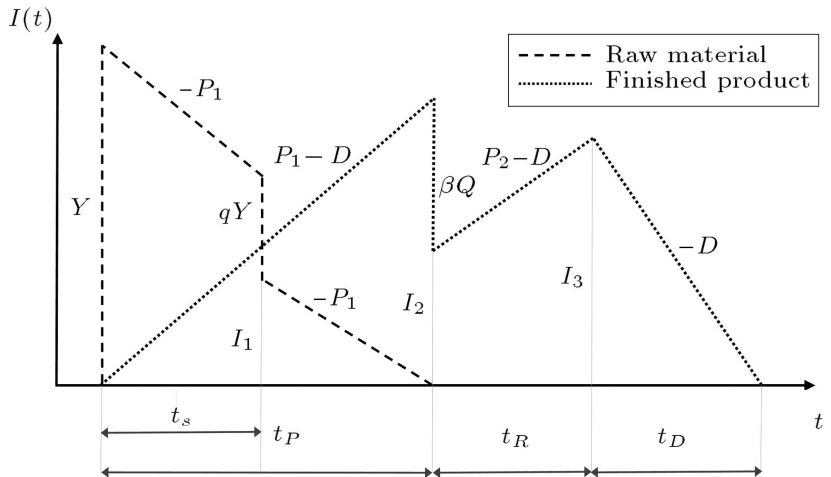

Figure 1. The inventory level for manufacturing system in Case I.

In the first scenario, production quantity, $Q$, is assumed to be a decision variable, independently. Hence, the total revenue per cycle, $T R_{I}$, involves sales of perfect and scrapped items given as $T R_{I}=v\{Q-$ $\beta Q+\alpha \beta Q\}+s\{(1-\alpha) \beta Q\}$, where $v$ and $s$ represent the unit selling prices of perfect and scrapped finished products, respectively. Note that the unit selling price of perfect products is greater than that of scrapped items $(v>s)$. The total cost in this case involves production, setup, holding, screening, and reworking costs. The production cost per cycle, $P C_{I}$, is calculated as $P C_{I}=C_{2} Q$. In addition, setup cost $S C_{I}$ is incurred per production cycle by $S C_{I}=A_{2}$. Moreover, in order to formulate the holding cost, the area at the inventory level in three periods, i.e., production period, $S_{1}$, rework period, $S_{2}$, and depletion period, $S_{3}$, is first calculated. The first area is calculated as $S_{1}=I_{\max } \cdot t_{p} / 2$. Since $I_{\max }=Q\left(1-D / P_{1}\right)$ and $t_{p}=Q / P_{1}, S_{1}$ is re-written as $S_{1}=\frac{Q^{2}}{2 P_{1}}\left(1-D / P_{1}\right)$. To calculate $S_{2}$, the inventory level at the start of rework period, $I_{2}$, and that at the end of rework period, $I_{3}$, as in $I_{2}=Q\left(1-D / P_{1}\right)-\beta Q$ and $I_{3}=Q(1-$ $\left.D / P_{1}\right)-\beta Q+\left(P_{2}-D\right) t_{R}$ should be first formulated. During rework period $t_{R}$, reworkable items, $\alpha \beta Q$, are in the reworking process. Hence, $t_{R}$ in terms of model parameters can be calculated as in $t_{R}=\alpha \beta Q / P_{2}$. Therefore, inventory level $I_{3}$ can be simplified as in $I_{3}=Q\left(1-D / P_{1}\right)-\beta Q+\alpha \beta Q\left(1-D / P_{2}\right)$. Therefore, the area at the inventory level in the rework period is calculated as in $S_{2}=t_{R}\left(I_{2}+I_{3}\right) / 2$, which can be rewritten as $S_{2}=\frac{\alpha \beta Q}{2 P_{2}}\left\{2 Q\left(1-D / P_{1}\right)-2 \beta Q+\alpha \beta Q(1-\right.$ $\left.\left.D / P_{2}\right)\right\}$. Moreover, the area at the inventory level in the depletion period is formulated as $S_{3}=I_{3} t_{D} / 2$ where the depletion period is $t_{D}=I_{3} / D$; hence, we have $S_{3}=I_{3}^{2} / 2 D$ which is re-written as follows:

$$
S_{3}=\frac{1}{2 D}\left\{Q\left(1-D / P_{1}\right)-\beta Q+\alpha \beta Q\left(1-D / P_{2}\right)\right\}^{2}
$$

By utilizing $S_{1}, S_{2}$, and $S_{3}$, the holding cost is formulated by $h_{2}\left\{S_{1}+S_{2}+S_{3}\right\}$ as follows: 


$$
\begin{aligned}
H C_{I}= & h_{2} Q^{2}\left\{\frac{G^{2}}{2 D}+\frac{1}{2 P_{1}}\left(1-\frac{D}{P_{1}}\right)\right. \\
& \left.+\frac{\alpha \beta}{2 P_{2}}\left\{\left(1-\frac{D}{P_{1}}\right)-\beta+G\right\}\right\},
\end{aligned}
$$

where $h_{2}$ is the holding cost per item per unit time and $G=\left(1-D / P_{1}\right)-\beta+\alpha \beta\left(1-D / P_{2}\right)$. The screening cost per cycle $W C_{I}$ is computed as $W C_{I}=d_{2} Q$ in which $d_{2}$ represents the screening cost of finished products per item. Moreover, the reworking cost per cycle, $R C_{I}$, is obtained through $R C_{I}=r \alpha \beta Q$, where $r$ denotes the rework cost per item.

Therefore, the total cost per cycle is obtained through $P C_{I}+S C_{I}+H C_{I}+W C_{I}+R C_{I}$ as follows:

$$
\begin{aligned}
T C_{I}= & C_{2} Q+A_{2}+h_{2} Q^{2}\left\{\frac{G^{2}}{2 D}+\frac{1}{2 P_{1}}\left(1-\frac{D}{P_{1}}\right)\right. \\
& \left.+\frac{\alpha \beta}{2 P_{2}}\left\{\left(1-\frac{D}{P_{1}}\right)-\beta+G\right\}\right\}+d_{2} Q+r \alpha \beta Q
\end{aligned}
$$

Here, the total profit per cycle in the first scenario of Case I, $T P_{I}$, can be calculated by $T R_{I}-T C_{I}$ as follows:

$$
\begin{aligned}
T P_{I}= & v\{Q-\beta Q+\alpha \beta Q\}+s\{(1-\alpha) \beta Q\}-C_{2} Q \\
& -A_{2}-h_{2} Q^{2}\left\{\frac{G^{2}}{2 D}+\frac{1}{2 P_{1}}\left(1-\frac{D}{P_{1}}\right)\right. \\
& \left.+\frac{\alpha \beta}{2 P_{2}}\left\{\left(1-\frac{D}{P_{1}}\right)-\beta+G\right\}\right\}-d_{2} Q-r \alpha \beta Q
\end{aligned}
$$

Since $\beta$ is random variable, it should be replaced with expected value $\mathrm{E}[\beta]$ in $T P_{I}$ to calculate expected total profit, $\mathrm{E}\left[T P_{I}\right]$, as follows:

$$
\begin{aligned}
& \mathrm{E}\left[T P_{I}\right]=v\{Q-\mathrm{E}[\beta] Q+\alpha \mathrm{E}[\beta] Q\}+s\{(1-\alpha) \mathrm{E}[\beta] Q\} \\
& -C_{2} Q-A_{2}-h_{2} Q^{2}\left\{\frac{\mathrm{E}[G]^{2}}{2 D}+\frac{1}{2 P_{1}}\left(1-\frac{D}{P_{1}}\right)\right. \\
& \left.\quad+\frac{\alpha \mathrm{E}[\beta]}{2 P_{2}}\left\{\left(1-\frac{D}{P_{1}}\right)-\mathrm{E}[\beta]+\mathrm{E}[G]\right\}\right\}-d_{2} Q \\
& -r \alpha \mathrm{E}[\beta] Q,
\end{aligned}
$$

where $\mathrm{E}[G]=\left(1-D / P_{1}\right)-\mathrm{E}[\beta]+\alpha \mathrm{E}[\beta]\left(1-D / P_{2}\right)$. Moreover, cycle time $T_{I}$ is also a random variable, which can be obtained by $T_{I}=t_{P}+t_{R}+t_{D}$ as $T_{I}=$ $\frac{Q}{D}(\beta(\alpha-1)+1)$, whose expected value is calculated as follows:

$$
\mathrm{E}\left[T_{I}\right]=\frac{Q}{D}(\mathrm{E}[\beta](\alpha-1)+1)
$$

Hence, the expected total profit per unit time is given as follows:

$$
E\left[T P U_{I}\right]=\frac{E\left[T P_{I}\right]}{E\left[T_{I}\right]} .
$$

By simplifying the expressions in Eq. (8), we obtain:

$$
\begin{aligned}
\mathrm{E}\left[T P U_{I}\right]= & \frac{D}{\mathrm{E}[\beta](\alpha-1)+1}\{v\{1-\mathrm{E}[\beta]+\alpha \mathrm{E}[\beta]\} \\
& +s\{(1-\alpha) \mathrm{E}[\beta]\}-C_{2}-\frac{A_{2}}{Q} \\
& -h_{2} Q\left\{\frac{\mathrm{E}[G]^{2}}{2 D}+\frac{1}{2 P_{1}}\left(1-\frac{D}{P_{1}}\right)\right. \\
& \left.+\frac{\alpha \mathrm{E}[\beta]}{2 P_{2}}\left\{\left(1-\frac{D}{P_{1}}\right)-\mathrm{E}[\beta]+\mathrm{E}[G]\right\}\right\} \\
& \left.-d_{2}-r \alpha \mathrm{E}[\beta]\right\} .
\end{aligned}
$$

The above expected total profit per unit time $\mathrm{E}\left[T P U_{I}\right]$ is concave, because:

$$
\frac{\partial^{2} \mathrm{E}\left[T P U_{I}\right]}{\partial Q^{2}}=\frac{-2 A_{2} D}{Q^{3}\{\mathrm{E}[\beta](\alpha-1)+1\}} \leq 0 .
$$

Therefore, the first derivative of $\mathrm{E}\left[T P U_{I}\right]$ can be set to zero so as to reach the economic lot size by Eq. (11) as shown in Box I. Here, the second scenario with both raw material and finished product cycles is considered. In this scenario, order quantity of raw material, $Y$, is the decision variable, and production quantity of finished product, $Q$, is the dependent variable. Since a fraction of raw material, $q$, is imperfect, then the relationship between order and production quantities is given as $Q=(1-q) Y$. After receiving many raw materials from an external source, a $100 \%$ screening process starts; simultaneously, the perfect raw materials go to production system under rate of $P_{1}$. This process continues until all of raw materials are inspected. Since the screening rate is constant, $x$, the duration of the

$$
Q_{I}^{*}=\left[\frac{2 A_{2} D}{h_{2}\left\{\mathrm{E}[G]^{2}+\frac{D}{P_{1}}\left(1-\frac{D}{P_{1}}\right)+\frac{\alpha D \mathrm{E}[\beta]}{P_{2}}\left\{\left(1-\frac{D}{P_{1}}\right)-\mathrm{E}[\beta]+\mathrm{E}[G]\right\}\right\}}\right]^{\frac{1}{2}}
$$


screening period is calculated, $t_{S}=Y / x$. Moreover, the quantity of produced items during the screening period is $t_{S} P_{1}$. In addition, the inventory level after disposal (selling) of imperfect raw materials is obtained through $I_{1}=Y-t_{S} P_{1}-q Y$, which is simplified, by substituting $t_{S}$, to $I_{1}=\left(1-q-P_{1} / x\right) Y$. The production period, $t_{p}$, is the time interval at which production quantity, $Q=(1-q) Y$, is processed. Therefore, it is computed as $t_{p}=Q / P_{1}$ or equivalently $t_{p}=(1-q) Y / P_{1}$. In this scenario, the total revenue per cycle, $T R_{I}$, involves sales of perfect and scrapped finished products and imperfect raw materials given as:

$$
\begin{aligned}
T R_{I}= & v\{(1-q) Y-\beta(1-q) Y+\alpha \beta(1-q) Y\} \\
& +s\{(1-\alpha) \beta(1-q) Y\}+p q Y .
\end{aligned}
$$

The total cost, in this scenario, is associated with two cycles, i.e., finished product cycle and raw material cycles. The total cost of finished product, $T C_{f p}$, similar to that of the first scenario, involves production, setup, holding, screening, and reworking costs. Hence, it can be simply obtained by substituting $Q=(1-q) Y$ into the total cost of the first scenario as follows:

$$
\begin{aligned}
T C_{f p}= & C_{2}(1-q) Y+A_{2} \\
& +h_{2}(1-q)^{2} Y^{2}\left\{\frac{G^{2}}{2 D}+\frac{1}{2 P_{1}}\left(1-\frac{D}{P_{1}}\right)\right. \\
& \left.+\frac{\alpha \beta}{2 P_{2}}\left\{\left(1-\frac{D}{P_{1}}\right)-\beta+G\right\}\right\} \\
& +d_{2}(1-q) Y+\operatorname{ro} \beta(1-q) Y .
\end{aligned}
$$

The total cost of raw material cycle, $T C_{r m}$, involves purchasing, ordering, holding, and screening costs. The purchasing cost of raw material per cycle is calculated as $C_{1} Y$. In addition, the ordering cost is incurred per cycle as $A_{1}$. Moreover, in order to formulate the holding cost, the area at the inventory level in two periods, i.e., screening period $S_{1}$ and after screening period (till end of production period) $S_{2}$, is first calculated. The first area is calculated as in $S_{1}=$ $\left\{Y+\left(q Y+I_{1}\right)\right\} t_{S} / 2$. By substituting $I_{1}$ and $t_{S}$ into $S_{1}$, it is simplified to $Y^{2}\left(2-P_{1} / x\right) /(2 x)$. In addition, the second area, $S_{2}$, is formulated as $S_{2}=I_{1}^{2} /\left(2 P_{1}\right)$, which is simplified to $S_{2}=Y^{2}\left(1-q-P_{1} / x\right)^{2} /\left(2 P_{1}\right)$. Hence, the total area as in $S_{1}+S_{2}=Y^{2}\left\{(1-q)^{2} /\left(2 P_{1}\right)+q / x\right\}$ can be calculated. Therefore, the holding cost of raw material is formulated as follows:

$$
H C_{r m}=h_{1} Y^{2}\left\{\frac{(1-q)^{2}}{2 P_{1}}+\frac{q}{x}\right\} \text {. }
$$

Now, the screening cost of raw material is calculated by $d_{1} Y$. Thus, the total cost of raw material cycle is obtained as follows:

$$
T C_{r m}=C_{1} Y+A_{1}+h_{1} Y^{2}\left\{\frac{(1-q)^{2}}{2 P_{1}}+\frac{q}{x}\right\}+d_{1} Y .
$$

Therefore, the total cost per cycle in the second scenario is obtained by $T C_{f p}+T C_{r m}$ as follows:

$$
\begin{aligned}
T C_{I}= & \left\{C_{1}+C_{2}(1-q)\right\} Y+A_{1}+A_{2} \\
& +h_{1} Y^{2}\left\{\frac{(1-q)^{2}}{2 P_{1}}+\frac{q}{x}\right\} \\
& +h_{2}(1-q)^{2} Y^{2}\left\{\frac{G^{2}}{2 D}+\frac{1}{2 P_{1}}\left(1-\frac{D}{P_{1}}\right)\right. \\
& \left.+\frac{\alpha \beta}{2 P_{2}}\left\{\left(1-\frac{D}{P_{1}}\right)-\beta+G\right\}\right\} \\
& +d_{1} Y+d_{2}(1-q) Y+r \alpha \beta(1-q) Y .
\end{aligned}
$$

Then, the total profit per cycle in the second scenario of Case I can be calculated by $T R_{I}-T C_{I}$ as follows:

$$
\begin{aligned}
T P_{I}= & v\{(1-q) Y-\beta(1-q) Y+\alpha \beta(1-q) Y\} \\
& +s\{(1-\alpha) \beta(1-q) Y\}+p q Y \\
& -\left\{C_{1}+C_{2}(1-q)\right\} Y-A_{1}-A_{2} \\
& -h_{1} Y^{2}\left\{\frac{(1-q)^{2}}{2 P_{1}}+\frac{q}{x}\right\} \\
& -h_{2}(1-q)^{2} Y^{2}\left\{\frac{G^{2}}{2 D}+\frac{1}{2 P_{1}}\left(1-\frac{D}{P_{1}}\right)\right. \\
& \left.+\frac{\alpha \beta}{2 P_{2}}\left\{\left(1-\frac{D}{P_{1}}\right)-\beta+G\right\}\right\} \\
& -d_{1} Y-d_{2}(1-q) Y-r \alpha \beta(1-q) Y .
\end{aligned}
$$

Since $\beta$ is a random variable, it should be replaced with expected value $\mathrm{E}[\beta]$ in $T P_{I}$ to calculate expected total profit, $\mathrm{E}\left[T P_{I}\right]$, as follows:

$$
\begin{aligned}
T P_{I}= & v\{(1-q) Y-\mathrm{E}[\beta](1-q) Y+\alpha \mathrm{E}[\beta](1-q) Y\} \\
& +s\{(1-\alpha) \mathrm{E}[\beta](1-q) Y\}+p q Y \\
& -\left\{C_{1}+C_{2}(1-q)\right\} Y-A_{1}-A_{2} \\
& -h_{1} Y^{2}\left\{\frac{(1-q)^{2}}{2 P_{1}}+\frac{q}{x}\right\} \\
& -h_{2}(1-q)^{2} Y^{2}\left\{\frac{\mathrm{E}[G]^{2}}{2 D}+\frac{1}{2 P_{1}}\left(1-\frac{D}{P_{1}}\right)\right. \\
& \left.+\frac{\alpha \mathrm{E}[\beta]}{2 P_{2}}\left\{\left(1-\frac{D}{P_{1}}\right)-\mathrm{E}[\beta]+\mathrm{E}[G]\right\}\right\} \\
& -d_{1} Y-d_{2}(1-q) Y-r \alpha \mathrm{E}[\beta](1-q) Y .
\end{aligned}
$$


Moreover, cycle time $T_{I}$, similar to that of the first scenario, is calculated as in $T_{I}=\frac{Q}{D}(\mathrm{E}[\beta](\alpha-1)+1)$ where $Q=(1-q) Y$. Hence, the expected total profit per unit time is given as follows:

$$
E\left[T P U_{I}\right]=\frac{E\left[T P_{I}\right]}{E\left[T_{I}\right]} .
$$

By simplifying the expressions in Eq. (18), we obtain:

$$
\begin{aligned}
& \mathrm{E}\left[T P U_{I}\right]=\frac{D}{\mathrm{E}[\beta](\alpha-1)+1}\{v\{1-\mathrm{E}[\beta]+\alpha \mathrm{E}[\beta]\} \\
& +s\{(1-\alpha) \mathrm{E}[\beta]\}+\frac{p q}{1-q}-\frac{C_{1}}{1-q}-C_{2}-\frac{A_{1}+A_{2}}{(1-q) Y} \\
& -\frac{h_{1}}{1-q} Y\left\{\frac{(1-q)^{2}}{2 P_{1}}+\frac{q}{x}\right\} h_{2}(1-q) Y\left\{\frac{\mathrm{E}[G]^{2}}{2 D}\right. \\
& +\frac{1}{2 P_{1}}\left(1-\frac{D}{P_{1}}\right)+\frac{\alpha \mathrm{E}[\beta]}{2 P_{2}}\left\{\left(1-\frac{D}{P_{1}}\right)-\mathrm{E}[\beta]\right. \\
& \left.+\mathrm{E}[G]\}\}-\frac{d_{1}}{1-q}-d_{2}-r \alpha \mathrm{E}[\beta]\right\} .
\end{aligned}
$$

The above expected total profit per unit time, $\mathrm{E}\left[T P U_{I}\right]$, is concave, because:

$$
\frac{\partial^{2} \mathrm{E}\left[T P U_{I}\right]}{\partial Y^{2}}=\frac{-2\left(A_{1}+A_{2}\right) D}{(1-q) Y^{3}\{\mathrm{E}[\beta](\alpha-1)+1\}} \leq 0 .
$$

Thus, the first derivative of $\mathrm{E}\left[T P U_{I}\right]$ can be set to zero so as to reach the economic lot size by Eq. (21) as shown in Box II.

\subsection{Case II: When shortage occurs and is fully backordered}

In addition, Figure 2 depicts the inventory level in Case II. Similar to the previous case, two scenarios of this case in the sequel are considered. In the first scenario, the finished product cycle is only considered and the raw material cycle is not considered, while, in the second scenario, both raw material and finished product cycles are considered, simultaneously.

Herein, the first scenario of Case II is addressed. Note that $t_{R 1}$ and $t_{R 2}$ represent the rework periods when inventory level is less than and greater than zero, respectively $\left(t_{R}=t_{R 1}+t_{R 2}\right)$. The total revenue per

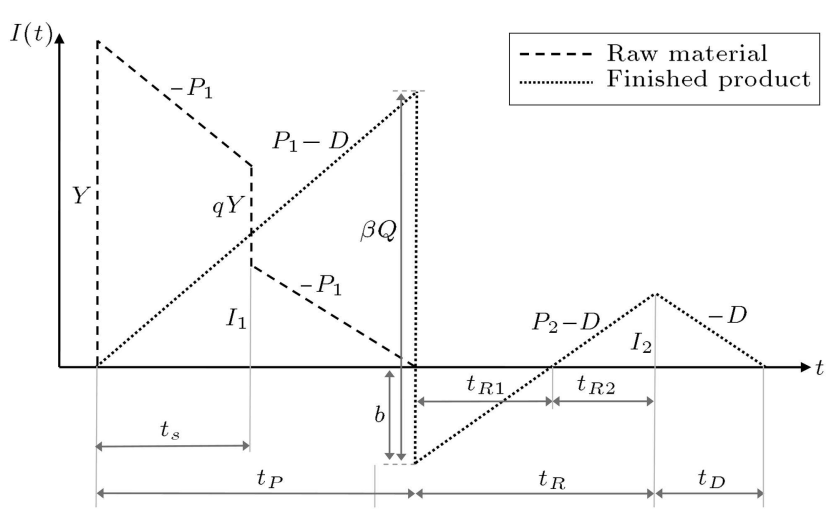

Figure 2. The inventory level for manufacturing system in Case II.

cycle in this case $T R_{\mathrm{II}}$ is similar to that of Case I, i.e., the sum of sales of perfect and reworked items and sales of scrapped items, given by $T R_{\mathrm{II}}=v\{Q-\beta Q+\alpha \beta Q\}+$ $s\{(1-\alpha) \beta Q\}$. The total cost in this case involves production, setup, holding, shortage, screening, and reworking costs. The production and setup costs per cycle are calculated as in $P C_{\mathrm{II}}=C_{2} Q$ and $S C_{\mathrm{II}}=A_{2}$. The area at the inventory level is classified into three periods, i.e., production period, $S_{1}$, rework period when inventory level is positive, $S_{2}$, and depletion period, $S_{3}$. The first area calculated as $S_{1}$ is similar to that of Case I which is given as $S_{1}=\frac{Q^{2}}{2 P_{1}}\left(1-D / P_{1}\right)$. To calculate $S_{2}$, the inventory level at the end of the rework period (start of the depletion period) via $I_{2}=$ $Q\left(1-D / P_{1}\right)-\beta Q+\left(P_{2}-D\right) t_{R}$ should be first obtained. By substituting $t_{R}=\alpha \beta Q / P_{2}$ into $I_{2}$, it is simplified to $I_{2}=Q\left(1-D / P_{1}\right)-\beta Q+\alpha \beta Q\left(1-D / P_{2}\right)$. Therefore, the area at the inventory level in the rework period is calculated as in $S_{2}=I_{2} \cdot t_{R 2} / 2$. Since $t_{R 1}$ is the time at which shortage quantity, $b=\beta Q-Q\left(1-D / P_{1}\right)$, is fully covered by reworked items, it can be calculated as in $t_{R 1}=b /\left(P_{2}-D\right)$, which can be re-written as $t_{R 1}=\left\{\beta Q-Q\left(1-D / P_{1}\right)\right\} /\left(P_{2}-D\right)$. Therefore, $t_{R 2}$ can be attained by $t_{R}-t_{R 1}$, which is summarized as $t_{R 2}=\alpha \beta Q / P_{2}-\left\{\beta Q-Q\left(1-D / P_{1}\right)\right\} /\left(P_{2}-D\right)$. Hence, $S_{2}$ can be expressed as follows:

$$
\begin{aligned}
S_{2}= & \frac{Q^{2}}{2\left(P_{2}-D\right)}\left\{\left(1-\frac{D}{P_{1}}\right)-\beta+\alpha \beta\left(1-\frac{D}{P_{2}}\right)\right\} \\
& \left\{\frac{\alpha \beta}{P_{2}}-\beta+\left(1-\frac{D}{P_{1}}\right)\right\} .
\end{aligned}
$$

$$
Y_{I}^{*}=\left[\frac{2\left(A_{1}+A_{2}\right) D}{h_{1} D\left\{\frac{(1-q)^{2}}{P_{1}}+\frac{2 q}{x}\right\}+h_{2}(1-q)^{2}\left\{\mathrm{E}[G]^{2}+\frac{D}{P_{1}}\left(1-\frac{D}{P_{1}}\right)+\frac{\alpha D \mathrm{E}[\beta]}{P_{2}}\left\{\left(1-\frac{D}{P_{1}}\right)-\mathrm{E}[\beta]+\mathrm{E}[G]\right\}\right\}}\right]^{\frac{1}{2}}
$$


Moreover, the area at the inventory level of the depletion period is formulated as $S_{3}=I_{2} \cdot t_{D} / 2$ where depletion period $t_{D}$ is $I_{2} / D$; hence, we have $S_{3}=$ $I_{2}^{2} /(2 D)$. By substituting $I_{2}$ into $S_{3}$, it can be rewritten as:

$$
S_{3}=\frac{1}{2 D}\left\{Q\left(1-D / P_{1}\right)-\beta Q+\alpha \beta Q\left(1-D / P_{2}\right)\right\}^{2} .
$$

By using $S_{1}, S_{2}$, and $S_{3}$, the holding cost is formulated as follows:

$$
\begin{aligned}
H C_{\mathrm{II}}= & h_{2} Q^{2}\left\{\frac{1}{2 P_{1}}\left(1-\frac{D}{P_{1}}\right)+\frac{G}{2\left(P_{2}-D\right)}\right. \\
& \left.\left\{\frac{\alpha \beta}{P_{2}}-\beta+\left(1-\frac{D}{P_{1}}\right)\right\}+\frac{G^{2}}{2 D}\right\} .
\end{aligned}
$$

In addition, the shortage cost is calculated as in $K C_{\mathrm{II}}=$ $\pi . b . t_{R 1} / 2$ where $\pi$ denotes the shortage cost per unit time per item. It can be re-expressed as follows:

$$
K C_{\mathrm{II}}=\pi \frac{Q^{2}}{P_{2}-D}\left\{\beta-\left(1-\frac{D}{P_{1}}\right)\right\}^{2} .
$$

The screening and reworking costs per cycle are computed as in $W C_{\mathrm{II}}=d_{2} Q$ and $R C_{I}=r \alpha \beta Q$, similar to those of Case I.

Therefore, the total cost per cycle in Case II is attained by $P C_{\mathrm{II}}+S C_{\mathrm{II}}+H C_{\mathrm{II}}+K C_{\mathrm{II}}+W C_{\mathrm{II}}+R C_{\mathrm{II}}$ as follows:

$$
\begin{aligned}
T C_{\mathrm{II}}= & C_{2} Q+A_{2}+h_{2} Q^{2}\left\{\frac{1}{2 P_{1}}\left(1-\frac{D}{P_{1}}\right)\right. \\
& \left.+\frac{G}{2\left(P_{2}-D\right)}\left\{\frac{\alpha \beta}{P_{2}}-\beta+\left(1-\frac{D}{P_{1}}\right)\right\}+\frac{G^{2}}{2 D}\right\} \\
& +\pi \frac{Q^{2}}{P_{2}-D}\left\{\beta-\left(1-\frac{D}{P_{1}}\right)\right\}^{2}+d_{2} Q+r \alpha \beta Q .
\end{aligned}
$$

Here, the total profit per cycle in Case II is calculated as follows:

$$
\begin{aligned}
T P_{\mathrm{II}}= & v\{Q-\beta Q+\alpha \beta Q\}+s\{(1-\alpha) \beta Q\} \\
& -C_{2} Q-A_{2}-h_{2} Q^{2}\left\{\frac{1}{2 P_{1}}\left(1-\frac{D}{P_{1}}\right)\right. \\
& \left.+\frac{G}{2\left(P_{2}-D\right)}\left\{\frac{\alpha \beta}{P_{2}}-\beta+\left(1-\frac{D}{P_{1}}\right)\right\}+\frac{G^{2}}{2 D}\right\} \\
& -\pi \frac{Q^{2}}{P_{2}-D}\left\{\beta-\left(1-\frac{D}{P_{1}}\right)\right\}^{2}-d_{2} Q-r \alpha \beta Q .
\end{aligned}
$$

Since $\beta$ is the random variable, it should be replaced by expected value $\mathrm{E}[\beta]$ in $T P_{\mathrm{II}}$ to calculate the expected total profit, $\mathrm{E}\left[T P_{\mathrm{II}}\right]$, as follows:

$$
\begin{aligned}
\mathrm{E}\left[T P_{\mathrm{II}}\right]= & v\{Q-\mathrm{E}[\beta] Q+\alpha \mathrm{E}[\beta] Q\} \\
& +s\{(1-\alpha) \mathrm{E}[\beta] Q\}-C_{2} Q-A_{2} \\
& -h_{2} Q^{2}\left\{\frac{1}{2 P_{1}}\left(1-\frac{D}{P_{1}}\right)\right. \\
& +\frac{\mathrm{E}[G]}{2\left(P_{2}-D\right)}\left\{\frac{\alpha \mathrm{E}[\beta]}{P_{2}}-\mathrm{E}[\beta]+\left(1-\frac{D}{P_{1}}\right)\right\} \\
& \left.+\frac{\mathrm{E}[G]^{2}}{2 D}\right\}-\pi \frac{Q^{2}}{P_{2}-D}\left\{\mathrm{E}[\beta]-\left(1-\frac{D}{P_{1}}\right)\right\}^{2} \\
& -d_{2} Q-r \alpha \mathrm{E}[\beta] Q .
\end{aligned}
$$

The cycle time $T_{\text {II }}$ in this case is obtained similar to that in Case I as $T_{\mathrm{II}}=\frac{Q}{D}(\beta(\alpha-1)+1)$, whose expected value is calculated as follows:

$$
\mathrm{E}\left[T_{\mathrm{II}}\right]=\frac{Q}{D}(\mathrm{E}[\beta](\alpha-1)+1)
$$

Hence, the expected total profit per unit time is calculated as follows:

$$
E\left[T P U_{\mathrm{II}}\right]=\frac{E\left[T P_{\mathrm{II}}\right]}{E\left[T_{\mathrm{II}}\right]}
$$

By simplifying the expressions in Eq. (28), we obtain:

$$
\begin{aligned}
& \mathrm{E}\left[T P U_{\mathrm{II}}\right]=\frac{D}{\mathrm{E}[\beta](\alpha-1)+1}\{v\{1-\mathrm{E}[\beta]+\alpha \mathrm{E}[\beta]\} \\
& +s\{(1-\alpha) \mathrm{E}[\beta]\}-C_{2}-\frac{A_{2}}{Q}-h_{2} Q\left\{\frac{1}{2 P_{1}}\left(1-\frac{D}{P_{1}}\right)\right. \\
& \left.+\frac{\mathrm{E}[G]}{2\left(P_{2}-D\right)}\left\{\frac{\alpha \mathrm{E}[\beta]}{P_{2}}-\mathrm{E}[\beta]+\left(1-\frac{D}{P_{1}}\right)\right\}+\frac{\mathrm{E}[G]^{2}}{2 D}\right\} \\
& \left.-\pi \frac{Q}{P_{2}-D}\left\{\mathrm{E}[\beta]-\left(1-\frac{D}{P_{1}}\right)\right\}^{2}-d_{2}-r \alpha \mathrm{E}[\beta]\right\} .
\end{aligned}
$$

This is also a concave function because:

$$
\frac{\partial^{2} \mathrm{E}\left[T P U_{\mathrm{II}}\right]}{\partial Q^{2}}=\frac{-2 A_{2} D}{Q^{3}\{\mathrm{E}[\beta](\alpha-1)+1\}} \leq 0 .
$$

Thus, the first derivative of $\mathrm{E}\left[T P U_{\mathrm{II}}\right]$ is set to zero so as to obtain the economic lot size by Eq. (31) as shown in Box III. Now, the second scenario of Case II is considered. Similar to the second scenario of Case I, the order quantity of raw material, $Y$, is the decision variable, and production quantity of finished product, $Q$, is the dependent variable calculated by $Q=(1-$ q) $Y$. The total revenue per cycle, $T R_{\mathrm{II}}$, is given as:

$$
\begin{aligned}
\mathrm{TR}_{\mathrm{II}}= & v\{(1-q) Y-\beta(1-q) Y+\alpha \beta(1-q) Y\} \\
& +s\{(1-\alpha) \beta(1-q) Y\}+p q Y .
\end{aligned}
$$




$$
Q_{\mathrm{II}}^{*}=\left[\frac{2 A_{2} D}{h_{2}\left\{\frac{D}{P_{1}}\left(1-\frac{D}{P_{1}}\right)+\frac{D \mathrm{E}[G]}{\left(P_{2}-D\right)}\left\{\frac{\alpha \mathrm{E}[\beta]}{P_{2}}-\mathrm{E}[\beta]+\left(1-\frac{D}{P_{1}}\right)\right\}+\frac{\mathrm{E}[G]^{2}}{2 D}\right\}+\frac{2 \pi D}{P_{2}-D}\left\{\mathrm{E}[\beta]-\left(1-\frac{D}{P_{1}}\right)\right\}^{2}}\right]^{\frac{1}{2}}
$$

Box III

The total cost of raw material, $T C_{r m}$, is similar to that of the second scenario of the first case. The total cost of finished product, $T C_{f p}$, is similar to that of the first scenario of this case, where order quantity is replaced with $Q=(1-q) Y$ as follows:

$$
\begin{aligned}
T C_{f p}= & C_{2}(1-q) Y+A_{2} \\
& +h_{2}(1-q)^{2} Y^{2}\left\{\frac{1}{2 P_{1}}\left(1-\frac{D}{P_{1}}\right)\right. \\
& \left.+\frac{G}{2\left(P_{2}-D\right)}\left\{\frac{\alpha \beta}{P_{2}}-\beta+\left(1-\frac{D}{P_{1}}\right)\right\}+\frac{G^{2}}{2 D}\right\} \\
& +\pi \frac{(1-q)^{2} Y^{2}}{P_{2}-D}\left\{\beta-\left(1-\frac{D}{P_{1}}\right)\right\}^{2} \\
& +d_{2}(1-q) Y+r \alpha \beta(1-q) Y .
\end{aligned}
$$

Therefore, the total cost per cycle of the second scenario is obtained by $T C_{f p}+T C_{r m}$ as follows:

$$
\begin{aligned}
T C_{\mathrm{II}}= & \left\{C_{1}+C_{2}(1-q)\right\} Y+A_{1}+A_{2} \\
& +h_{1} Y^{2}\left\{\frac{(1-q)^{2}}{2 P_{1}}+\frac{q}{x}\right\} \\
& +h_{2}\left(1-q^{2}\right) Y^{2}\left\{\frac{1}{2 P_{1}}\left(1-\frac{D}{P_{1}}\right)\right. \\
& \left.+\frac{G}{2\left(P_{2}-D\right)}\left\{\frac{\alpha \beta}{P_{2}}-\beta+\left(1-\frac{D}{P_{1}}\right)\right\}+\frac{G^{2}}{2 D}\right\} \\
& +\pi \frac{(1-q)^{2} Y^{2}}{P_{2}-D}\left\{\beta-\left(1-\frac{D}{P_{1}}\right)\right\}^{2} \\
& +d_{1} Y+d_{2}(1-q) Y+r \alpha \beta(1-q) Y .
\end{aligned}
$$

Then, the total profit per cycle in the second scenario of Case II can be calculated by $T R_{\mathrm{II}}-T C_{\mathrm{II}}$ as follows:

$$
\begin{aligned}
T P_{\mathrm{II}}= & v\{(1-q) Y-\beta(1-q) Y+\alpha \beta(1-q) Y\} \\
& +s\{(1-\alpha) \beta(1-q) Y\}+p q Y \\
& -\left\{C_{1}+C_{2}(1-q)\right\} Y-A_{1}-A_{2}
\end{aligned}
$$

$$
\begin{aligned}
& -h_{1} Y^{2}\left\{\frac{(1-q)^{2}}{2 P_{1}}+\frac{q}{x}\right\} \\
& -h_{2}(1-q)^{2} Y^{2}\left\{\frac{1}{2 P_{1}}\left(1-\frac{D}{P_{1}}\right)\right. \\
& \left.+\frac{G}{2\left(P_{2}-D\right)}\left\{\frac{\alpha \beta}{P_{2}}-\beta+\left(1-\frac{D}{P_{1}}\right)\right\}+\frac{G^{2}}{2 D}\right\} \\
& -\pi \frac{(1-q)^{2} Y^{2}}{P_{2}-D}\left\{\beta-\left(1-\frac{D}{P_{1}}\right)\right\}^{2} \\
& -d_{1} Y-d_{2}(1-q) Y-r \alpha \beta(1-q) Y .
\end{aligned}
$$

Since $\beta$ is the random variable, it should be replaced with expected value $\mathrm{E}[\beta]$ in $T P_{\mathrm{II}}$ to calculate the expected total profit, $\mathrm{E}\left[T P_{\mathrm{II}}\right]$, as follows:

$$
\begin{aligned}
E\left[T P_{\mathrm{II}}\right]=v\{(1-q) Y-E[\beta](1-q) Y & \\
& +\alpha E[\beta](1-q) Y\}+s\{(1-\alpha) E[\beta](1-q) Y\}+p q Y \\
& -\left\{C_{1}+C_{2}(1-q)\right\} Y-A_{1}-A_{2} \\
& -h_{1} Y^{2}\left\{\frac{(1-q)^{2}}{2 P_{1}}+\frac{q}{x}\right\} \\
& -h_{2}(1-q)^{2} Y^{2}\left\{\frac{1}{2 P_{1}}\left(1-\frac{D}{P_{1}}\right)\right. \\
& +\frac{E[G]}{2\left(P_{2}-D\right)}\left\{\frac{\alpha E[\beta]}{P_{2}}-E[\beta]+\left(1-\frac{D}{P_{1}}\right)\right\} \\
& \left.+\frac{E[G]^{2}}{2 D}\right\}-\pi \frac{(1-q)^{2} Y^{2}}{P_{2}-D}\left\{E[\beta]-\left(1-\frac{D}{P_{1}}\right)\right\}^{2} \\
& -d_{1} Y-d_{2}(1-q) Y-r \alpha E[\beta](1-q) Y .
\end{aligned}
$$

Moreover, the expected cycle time, $\mathrm{E}\left[T_{\mathrm{II}}\right]$, similar to that of the first scenario, is $\mathrm{E}\left[T_{\mathrm{II}}\right]=\frac{Q}{D}(\mathrm{E}[\beta](\alpha-1)+1)$ where $Q=(1-q) Y$. Hence, the expected total profit per unit time is given as follows:

$$
E\left[T P U_{\mathrm{II}}\right]=\frac{E\left[T P_{\mathrm{II}}\right]}{E\left[T_{\mathrm{II}}\right]}
$$

By simplifying the expressions in Eq. (36), we obtain: 


$$
\begin{aligned}
\mathrm{E}\left[T P U_{\mathrm{II}}\right] & =\frac{D}{\mathrm{E}[\beta](\alpha-1)+1}\{v\{1-\mathrm{E}[\beta]+\alpha \mathrm{E}[\beta]\} \\
& +s\{(1-\alpha) \mathrm{E}[\beta]\}+\frac{p q}{1-q}-\frac{C_{1}}{1-q}-C_{2} \\
& -\frac{A_{1}+A_{2}}{(1-q) Y}-\frac{h_{1}}{1-q} Y\left\{\frac{(1-q)^{2}}{2 P_{1}}+\frac{q}{x}\right\} \\
& -h_{2}(1-q) Y\left\{\frac{1}{2 P_{1}}\left(1-\frac{D}{P_{1}}\right)\right. \\
& +\frac{\mathrm{E}[G]}{2\left(P_{2}-D\right)}\left\{\frac{\alpha \mathrm{E}[\beta]}{P_{2}}-\mathrm{E}[\beta]+\left(1-\frac{D}{P_{1}}\right)\right\} \\
& \left.+\frac{\mathrm{E}[G]^{2}}{2 D}\right\}-\pi \frac{(1-q) Y}{P_{2}-D}\left\{\mathrm{E}[\beta]-\left(1-\frac{D}{P_{1}}\right)\right\}^{2} \\
& -\frac{d_{1}}{1-q}-d_{2}-r \alpha \mathrm{E}[\beta] .
\end{aligned}
$$

The above expected total profit per unit time, $\mathrm{E}\left[T P U_{\mathrm{I}}\right]$, is concave because:

$$
\frac{\partial^{2} \mathrm{E}\left[T P U_{\mathrm{II}}\right]}{\partial Y^{2}}=\frac{-2\left(A_{1}+A_{2}\right) D}{(1-q) Y^{3}\{\mathrm{E}[\beta](\alpha-1)+1\}} \leq 0 .
$$

Thus, the first derivative of $\mathrm{E}\left[T P U_{\mathrm{II}}\right]$ is set to zero so as to attain the economic lot size by Eq. (39) as shown in Box IV.

\subsection{Case III: When shortage occurs and is partially backordered}

Here, Case III as shown by Figure 3 is analyzed. Similar to the previous cases, two scenarios of this case in this section are considered. In the first scenario, the finished product cycle is only considered, and the raw material cycle is not considered, while, in the second scenario, both raw material and finished product cycles are considered, simultaneously.

First, the first scenario of this case will be dis-

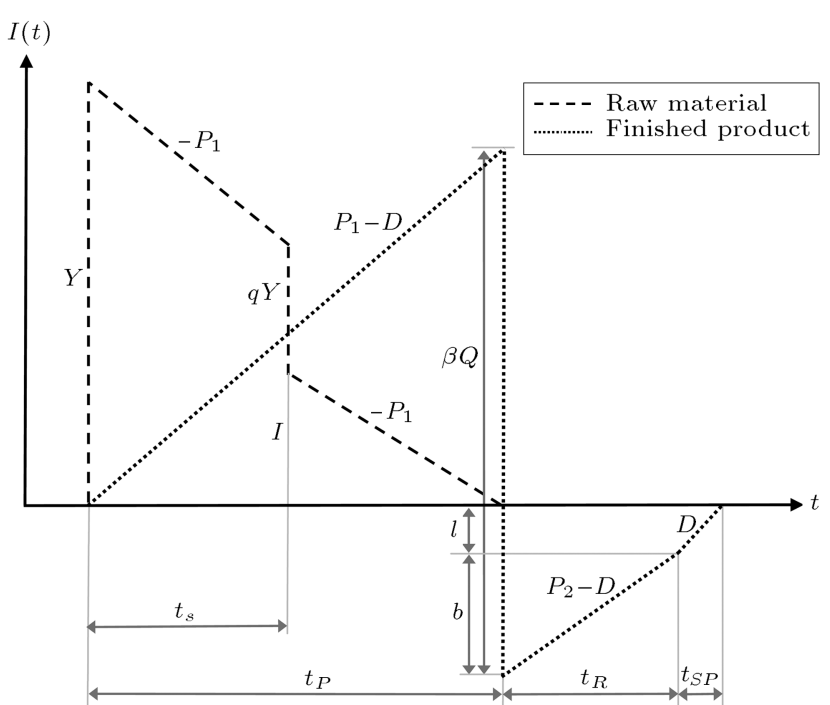

Figure 3. The inventory level for manufacturing system in Case III.

cussed. As can be seen, all of the shortages cannot be backordered by reworked items in this case and, hence, some amount of shortage is backordered $(b)$ and others are not satisfied at this moment $(l)$. To avoid lost sale, a special order of products at the end of the rework period is used whenever this case occurs. Indeed, the manufacturer uses a service from an external producer to fulfill the unsatisfied demand. This special order is received gradually within interval $t_{S P}$. In this case, the total revenue per cycle in this case, $T R_{\text {III }}$, equals the sum of sales of perfect and reworked items and sales of scrapped items, given by $T R_{\mathrm{III}}=v\{Q-\beta Q+\alpha \beta Q\}+s\{(1-\alpha) \beta Q\}$. The total cost involves production, setup, holding, shortage, screening, and reworking costs. The production and setup costs per cycle are calculated as in $P C_{\mathrm{III}}=C_{2} Q$ and $S C_{\mathrm{III}}=A_{2}$. The area at the inventory level in production period, $S_{1}$, is similar to those of Cases I and II, which is given as $S_{1}=\frac{Q^{2}}{2 P_{1}}\left(1-D / P_{1}\right)$. Then, the holding cost is calculated as follows:

$$
Y_{\mathrm{II}}^{*}=\left[\begin{array}{c}
\frac{2\left(A_{1}+A_{2}\right) D}{h_{1} D\left\{\frac{(1-q)^{2}}{P_{1}}+\frac{2 q}{x}\right\}+h_{2}(1-q)^{2}\left\{\frac{D}{P_{1}}\left(1-\frac{D}{P_{1}}\right)\right.} \\
\left.\quad+\frac{D \mathrm{E}[G]}{\left(P_{2}-D\right)}\left\{\frac{\alpha \mathrm{E}[\beta]}{P_{2}}-\mathrm{E}[\beta]+\left(1-\frac{D}{P_{1}}\right)\right\}+\mathrm{E}[G]^{2}\right\}+2 \pi D \frac{(1-q)^{2}}{P_{2}-D}\left\{\mathrm{E}[\beta]-\left(1-\frac{D}{P_{1}}\right)\right\}^{2}
\end{array}\right]^{\frac{1}{2}}
$$




$$
H C_{\mathrm{III}}=h_{2} \frac{Q^{2}}{2 P_{1}}\left(1-\frac{D}{P_{1}}\right) .
$$

In addition, the shortage cost is calculated as $K C_{\text {III }}=$ $\pi\left\{S_{2}+S_{3}\right\}$, where $S_{2}$ and $S_{3}$ represent the rework and special order periods, respectively. To calculate $S_{2}$, the backordered and unsatisfied demand quantities should be first obtained. As can be seen in Figure 3, the sum of backordered and unsatisfied demands is $b+l=\beta Q-I_{\max }$, which is simplified to $\beta Q-Q(1-$ $\left.D / P_{1}\right)$. On the other hand, $b$ equals $\left(P_{2}-D\right) t_{R}$ which is simplified by substituting $t_{R}=\alpha \beta Q / P_{2}$ to $b=\alpha \beta Q\left(1-D / P_{2}\right)$. Therefore, the unsatisfied demand at the end of the rework period is attained as in $l=Q\left(1-D / P_{1}\right)-\beta Q+\alpha \beta Q\left(1-D / P_{2}\right)$. Here, the shortage area at the inventory level in the rework period as $S_{2}=(b+2 l) \cdot t_{R} / 2$ can be calculated. By substituting $b, l$, and $t_{R}$ into $S_{2}$, it can be expressed as follows:

$$
S_{2}=\frac{\alpha \beta Q}{2 P_{2}}\left\{\alpha \beta Q\left(1-\frac{D}{P_{2}}\right)-2 G Q\right\} .
$$

In addition, the third area under curve is calculated as $S_{3}=l . t_{S P} / 2$, where special order period $t_{S P}$ is $l / D$; hence, we reach $S_{3}=l^{2} /(2 D)$. By substituting $l$ into $S_{3}$, it can be re-written as follows:

$$
S_{3}=\frac{G^{2} Q^{2}}{2 D} \text {. }
$$

By using $S_{2}$ and $S_{3}$, the shortage cost is calculated as follows:

$$
K C_{\mathrm{III}}=\pi Q^{2}\left\{\frac{\alpha \beta}{2 P_{2}}\left\{\alpha \beta\left(1-\frac{D}{P_{2}}\right)-2 G\right\}+\frac{G^{2}}{2 D}\right\} .
$$

The screening and reworking costs per cycle are computed as in $W C_{\mathrm{III}}=d_{2} Q$ and $R C_{\mathrm{III}}=r \alpha \beta Q$ similar to those of Cases I and II.

Therefore, the total cost per cycle in Case III is calculated by $P C_{\mathrm{III}}+S C_{\mathrm{III}}+H C_{\mathrm{III}}+K C_{\mathrm{III}}+W C_{\mathrm{III}}+$ $R C_{\text {III }}$ as follows:

$$
\begin{aligned}
T C_{\mathrm{III}}= & C_{2} Q+A_{2}+h_{2} \frac{Q^{2}}{2 P_{1}}\left(1-\frac{D}{P_{1}}\right) \\
& +\pi Q^{2}\left\{\frac{\alpha \beta}{2 P_{2}}\left\{\alpha \beta\left(1-\frac{D}{P_{2}}\right)-2 G\right\}+\frac{G^{2}}{2 D}\right\} \\
& +d_{2} Q+r \alpha \beta Q .
\end{aligned}
$$

Furthermore, the total profit per cycle in Case III is attained as follows:

$$
\begin{aligned}
T P_{\text {III }}= & v\{Q-\beta Q+\alpha \beta Q\}+s\{(1-\alpha) \beta Q\} \\
& -C_{2} Q-A_{2}-h_{2} \frac{Q^{2}}{2 P_{1}}\left(1-\frac{D}{P_{1}}\right)
\end{aligned}
$$

$$
\begin{aligned}
& -\pi Q^{2}\left\{\frac{\alpha \beta}{2 P_{2}}\left\{\alpha \beta\left(1-\frac{D}{P_{2}}\right)-2 G\right\}+\frac{G^{2}}{2 D}\right\} \\
& -d_{2} Q-r \alpha \beta Q .
\end{aligned}
$$

The defective rate is replaced with expected value $\mathrm{E}[\beta]$ to calculate expected total profit, $\mathrm{E}\left[T P_{\mathrm{III}}\right]$, as follows:

$$
\begin{aligned}
\mathrm{E}\left[T P_{\mathrm{III}}\right]= & v\{Q-\mathrm{E}[\beta] Q+\alpha \mathrm{E}[\beta] Q\}+s\{(1-\alpha) \mathrm{E}[\beta] Q\} \\
& -C_{2} Q-A_{2}-h_{2} \frac{Q^{2}}{2 P_{1}}\left(1-\frac{D}{P_{1}}\right) \\
& -\pi Q^{2}\left\{\frac{\alpha \mathrm{E}[\beta]}{2 P_{2}}\left\{\alpha \mathrm{E}[\beta]\left(1-\frac{D}{P_{2}}\right)-2 \mathrm{E}[G]\right\}\right. \\
& \left.+\frac{\mathrm{E}[G]^{2}}{2 D}\right\}-d_{2} Q-r \alpha \mathrm{E}[\beta] Q .
\end{aligned}
$$

Cycle time $T_{\mathrm{III}}$ is obtained by $T_{\mathrm{III}}=t_{P}+t_{R}+t_{S P}$ as follows:

$$
T_{\mathrm{III}}=\frac{Q}{D}(\beta(\alpha-1)+1)
$$

Note that $T_{\text {III }} \geq 0$. The expected total profit per unit time is given as follows:

$$
E\left[T P U_{\mathrm{III}}\right]=\frac{E\left[T P_{\mathrm{III}}\right]}{E\left[T_{\mathrm{III}}\right]} .
$$

By simplifying the expressions in Eq. (48), we obtain:

$$
\begin{aligned}
& \mathrm{E}\left[T P U_{\mathrm{III}}\right]=\frac{D}{\mathrm{E}[\beta](\alpha-1)+1}\{v\{1-\mathrm{E}[\beta]+\alpha \mathrm{E}[\beta]\} \\
& +s\{(1-\alpha) \mathrm{E}[\beta]\}-C_{2}-\frac{A_{2}}{Q}-h_{2} \frac{Q}{2 P_{1}}\left(1-\frac{D}{P_{1}}\right) \\
& -\pi Q\left\{\frac{\alpha \mathrm{E}[\beta]}{2 P_{2}}\left\{\alpha \mathrm{E}[\beta]\left(1-\frac{D}{P_{2}}\right)-2 \mathrm{E}[G]\right\}\right. \\
& \left.\left.+\frac{\mathrm{E}[G]^{2}}{2 D}\right\}-d_{2}-r \alpha \mathrm{E}[\beta]\right\} .
\end{aligned}
$$

This is a concave function because:

$$
\frac{\partial^{2} \mathrm{E}\left[T P U_{\text {III }}\right]}{\partial Q^{2}}=\frac{-2 A_{2} D}{Q^{3}\{\mathrm{E}[\beta](\alpha-1)+1\}} \leq 0 .
$$

Thus, the first derivative of $\mathrm{E}\left[T P U_{\mathrm{III}}\right]$ can be set to zero so as to calculate the economic lot size by Eq. (51) as shown in Box V. Now, the second scenario of Case III is considered. Similar to the second scenario of the previous cases, the order quantity of raw material $Y$ is the decision variable, and production quantity of finished product, $Q$, is the dependent variable calculated by $Q=(1-q) Y$. The total revenue per cycle, $T R_{\mathrm{III}}$, 


$$
Q_{\mathrm{III}}^{*}=\left[\frac{2 A_{2} D}{h_{2}\left\{\frac{D}{P_{1}}\left(1-\frac{D}{P_{1}}\right)\right\}+\pi\left\{\frac{\alpha D \mathrm{E}[\beta]}{P_{2}}\left\{\alpha \mathrm{E}[\beta]\left(1-\frac{D}{P_{2}}\right)-2 \mathrm{E}[G]\right\}+\mathrm{E}[G]^{2}\right\}}\right]^{\frac{1}{2}} .
$$

\section{Box V}

and the total cost of raw material, $T C_{r m}$, are similar to those of the second scenario of the previous cases. The total cost of finished product, $T C_{f p}$, is similar to that of the first scenario of the current case, where order quantity is replaced with $Q=(1-q) Y$ as follows:

$$
\begin{aligned}
T C_{f p}= & C_{2}(1-q) Y+A_{2}+h_{2} \frac{(1-q)^{2} Y^{2}}{2 P_{1}}\left(1-\frac{D}{P_{1}}\right) \\
& +\pi(1-q)^{2} Y^{2}\left\{\frac{\alpha \beta}{2 P_{2}}\left\{\alpha \beta\left(1-\frac{D}{P_{2}}\right)-2 G\right\}\right. \\
& \left.+\frac{G^{2}}{2 D}\right\}+d_{2}(1-q) Y+r \alpha \beta(1-q) Y
\end{aligned}
$$

Therefore, the total cost per cycle of the second scenario is obtained by $T C_{f p}+T C_{r m}$ as follows:

$$
\begin{aligned}
T C_{\mathrm{III}}= & \left\{C_{1}+C_{2}(1-q)\right\} Y+A_{1}+A_{2} \\
& +h_{1} Y^{2}\left\{\frac{(1-q)^{2}}{2 P_{1}}+\frac{q}{x}\right\} \\
& +h_{2} \frac{(1-q)^{2} Y^{2}}{2 P_{1}}\left(1-\frac{D}{P_{1}}\right) \\
& +\pi(1-q)^{2} Y^{2}\left\{\frac{\alpha \beta}{2 P_{2}}\left\{\alpha \beta\left(1-\frac{D}{P_{2}}\right)-2 G\right\}\right. \\
& \left.+\frac{G^{2}}{2 D}\right\}+d_{1} Y+d_{2}(1-q) Y+r \alpha \beta(1-q) Y .(53)
\end{aligned}
$$

Then, the total profit per cycle in the second scenario of Case III can be calculated by $T R_{\mathrm{III}}-T C_{\mathrm{III}}$ as follows:

$$
\begin{aligned}
T P_{\text {III }}= & v\{(1-q) Y-\beta(1-q) Y+\alpha \beta(1-q) Y\} \\
& +s\{(1-\alpha) \beta(1-q) Y\}+p q Y \\
& -\left\{C_{1}+C_{2}(1-q)\right\} Y-A_{1}-A_{2} \\
& -h_{1} Y^{2}\left\{\frac{(1-q)^{2}}{2 P_{1}}+\frac{q}{x}\right\} \\
& -h_{2} \frac{(1-q)^{2} Y^{2}}{2 P_{1}}\left(1-\frac{D}{P_{1}}\right)
\end{aligned}
$$

$$
\begin{aligned}
& -\pi(1-q)^{2} Y^{2}\left\{\frac{\alpha \beta}{2 P_{2}}\left\{\alpha \beta\left(1-\frac{D}{P_{2}}\right)-2 G\right\}\right. \\
& \left.+\frac{G^{2}}{2 D}\right\}-d_{1} Y-d_{2}(1-q) Y-r \alpha \beta(1-q) Y .
\end{aligned}
$$

The expected total profit, $\mathrm{E}\left[T P_{\mathrm{III}}\right]$, is calculated as follows:

$$
\begin{aligned}
& E[T P]_{\mathrm{III}}=v\{(1-q) Y-E[\beta](1-q) Y+\alpha E[\beta](1-q) Y\} \\
& +s\{(1-\alpha) E[\beta](1-q) Y\}+p q Y \\
& -\left\{C_{1}+C_{2}(1-q)\right\} Y-A_{1}-A_{2} \\
& \quad-h_{1} Y^{2}\left\{\frac{(1-q)^{2}}{2 P_{1}}+\frac{q}{x}\right\} \\
& -h_{2} \frac{(1-q)^{2} Y^{2}}{2 P_{1}}\left(1-\frac{D}{P_{1}}\right) \\
& \quad-\pi(1-q)^{2} Y^{2}\left\{\frac{\alpha E[\beta]}{2 P_{2}}\left\{\alpha E[\beta]\left(1-\frac{D}{P_{2}}\right)-2 G\right\}\right. \\
& \left.+\frac{E[G]^{2}}{2 D}\right\}-d_{1} Y-d_{2}(1-q) Y-r \alpha E[\beta](1-q) Y .(55)
\end{aligned}
$$

Moreover, the cycle time is similar to that of the first scenario where $Q=(1-q) Y$. Hence, the expected total profit per unit time is given as follows:

$$
E\left[T P U_{\mathrm{III}}\right]=\frac{E\left[T P_{\mathrm{III}}\right]}{E\left[T_{\mathrm{III}}\right]}
$$

By simplifying the expressions in Eq. (56), we obtain:

$$
\begin{aligned}
\mathrm{E}\left[T P U_{\mathrm{III}}\right] & =\frac{D}{\mathrm{E}[\beta](\alpha-1)+1}\{v\{1-\mathrm{E}[\beta]+\alpha \mathrm{E}[\beta]\} \\
& +s\{(1-\alpha) \mathrm{E}[\beta]\}+\frac{p q}{1-q}-\frac{C_{1}}{1-q} \\
& -C_{2}-\frac{A_{1}+A_{2}}{(1-q) Y}-\frac{h_{1}}{1-q} Y\left\{\frac{(1-q)^{2}}{2 P_{1}}+\frac{q}{x}\right\} \\
& -h_{2} \frac{(1-q) Y}{2 P_{1}}\left(1-\frac{D}{P_{1}}\right)-\pi(1-q) Y
\end{aligned}
$$




$$
\begin{aligned}
& \left\{\frac{\alpha \mathrm{E}[\beta]}{2 P_{2}}\left\{\alpha \mathrm{E}[\beta]\left(1-\frac{D}{P_{2}}\right)-2 \mathrm{E}[G]\right\}\right. \\
& \left.\left.+\frac{\mathrm{E}[G]^{2}}{2 D}\right\}-\frac{d_{1}}{1-q}-d_{2}-r \alpha \mathrm{E}[\beta]\right\} .
\end{aligned}
$$

The above expected total profit per unit time, $\mathrm{E}\left[T P U_{\mathrm{III}}\right]$, is concave because:

$$
\frac{\partial^{2} \mathrm{E}\left[T P U_{\mathrm{III}}\right]}{\partial Y^{2}}=\frac{-2\left(A_{1}+A_{2}\right) D}{(1-q) Y^{3}\{\mathrm{E}[\beta](\alpha-1)+1\}} \leq 0
$$

Therefore, the first derivative of $\mathrm{E}\left[T P U_{\mathrm{III}}\right]$ can be set to zero so as to gain the economic lot size by Eq. (59) as shown in Box VI.

\section{Illustrative experiments}

We are going to present and discuss a numerical example in this section. Let us consider a manufacturer that orders raw materials from an external supplier with purchase cost, $C_{1}=10$, units of money per item and ordering cost, $A_{1}=250$, units of money per order. Then, the manufacturer produces finished products via a finite production rate, $P_{1}=200$, units per month with production cost, $C_{2}=20$, units of money per item. The demand rate for this product is $D=100$ units per month. In addition, assume that the machine setup cost is $A_{2}=150$ units of money per production cycle. Moreover, the holding costs of raw materials and finished products are $h_{1}=2$ and $h_{2}=5$ units of money per item per unit time. The raw materials contain imperfect quality items with the rate of $q=0.12$, and a $100 \%$ screening process is carried out on lot-size receipt with the rate of $x=100$ units per month. On the other hand, the production system is also defective and a fraction of finished products is imperfect. It is assumed that the defective rate follows a uniform distribution at an interval of $0.08-0.12(\beta \sim$ Unifom $(0.08,0.12))$.
Therefore, the expected value of defective rate $\beta$ is calculated as follows:

$$
\begin{aligned}
\mathrm{E}[\beta] & =\int_{a}^{b} \beta f(\beta) d \beta=\int_{a}^{b} \beta \frac{1}{b-a} d \beta=\frac{a+b}{2} \\
& =\frac{0.08+0.12}{2}=0.10 .
\end{aligned}
$$

The screening costs for raw materials and finished products are $d_{1}=5$ and $d_{2}=10$ units of money per item. The perfect finished products are sold at price $v=50$ units of money per item. The imperfect raw materials are sold after the screening process with price $p=2$ units of money per item, while the defective finished products go under a further rework process with rework rate $P_{2}=250$ units per month and rework cost $r=5$ units of money. The number of defective products is reworkable $(\alpha=0.8)$ and has the potential to become perfect after the reworking process, while others are scrapped items and sold at a lower price, $s=8$. Moreover, the backorder shortage cost is $\pi=4$ units of money per item per unit time. Since the defective rate of a machine is a random variable, three cases are possible regarding the occurrence of backordering shortage. Table 1 presents the optimal results for decision variables and total profits.

To select the optimal solution for this example, the optimal case should be selected. As discussed before, if the defective rate falls within 0 and 1 $D / P_{1}(0.50)$, the first case is satisfied; else, if the defective rate falls within $1-D / P_{1}(0.50)$ and $(1-$ $\left.D / P_{1}\right) /\left\{1-\alpha\left(1-D / P_{2}\right)\right\}(0.9615)$, the second case is true; otherwise, the third case is selected. Since the expected value of the defective rate is 0.1 which falls within the first interval, the optimal solution is that of the first one. To further analyze the obtained results, three cases are compared together, here. As can be seen, the optimal cycle time $(T)$ decreases from the first case to the third one. The third case has higher

$$
Y_{\mathrm{III}}^{*}=\left[\frac{2\left(A_{1}+A_{2}\right) D}{h_{1} D\left\{\frac{(1-q)^{2}}{P_{1}}+\frac{2 q}{x}\right\}+h_{2} D \frac{(1-q)^{2}}{P_{1}}\left(1-\frac{D}{P_{1}}\right)+\pi(1-q)^{2}\left\{\frac{\alpha D \mathrm{E}[\beta]}{P_{2}}\left\{\alpha \mathrm{E}[\beta]\left(1-\frac{D}{P_{2}}\right)-2 \mathrm{E}[G]\right\}+\mathrm{E}[G]^{2}\right\}}\right]^{\frac{1}{2}}
$$

Box VI

Table 1. Optimal decision variables and total profits for numerical example.

\begin{tabular}{cccccc}
\hline Case & $\boldsymbol{T}$ & $\boldsymbol{Y}$ & $\boldsymbol{Q}$ & $\boldsymbol{T P}$ & $\boldsymbol{T P U}$ \\
\hline I & 1.3844 & 160.5249 & 141.2619 & 13324.3935 & 9624.9013 \\
II & 1.2012 & 139.2910 & 122.5760 & 11456.0446 & 9536.8074 \\
III & 1.4682 & 170.2499 & 149.8199 & 15992.9981 & 10892.6655 \\
\hline
\end{tabular}


optimal order and production quantities ( $Y$ and $Q$ ), while the first and second ones have the next higher quantities, respectively. An important observation of the optimal solution for this example is that the third case shows the best achievement in terms of both Total Profit $(T P)$ and Total Profit per time Unit $(T P U)$ among all cases. Of course, this result is just true for these special parameters, and further results can be obtained via sensitivity analysis. Therefore, an analysis is performed by changing the value of input parameters in order to assess the outputs under various inputs.

The consideration of raw materials, backordering shortage, and reworking are essential issues in our proposed manufacturing model. Thus, some analyses are carried out here by a change in imperfect rate $q$, holding cost $h_{1}$ of raw materials, shortage cost of finished products $\pi$, and percentage of reworkable items $\alpha$, while all other parameters are kept unchanged. The results are depicted in Figures 4-19. Moreover, Tables 2-4 summarize the results for each case, depicted in these figures, at a glance. Based on Figures 4-11, it is clear that when the imperfect rate for raw materials $(q)$ and holding cost $\left(h_{1}\right)$ increases, the total profit of three cases becomes close to each other. Moreover, when the imperfect rate for raw materials $(q)$ tends to 1 , the problem tends to become unbeneficial. According to Figures 8 and 9 , it can be seen that when holding cost increases, all of outputs (order size, production size, and total profits) decrease significantly. Since, in Case I, there is no shortage of finished products, the

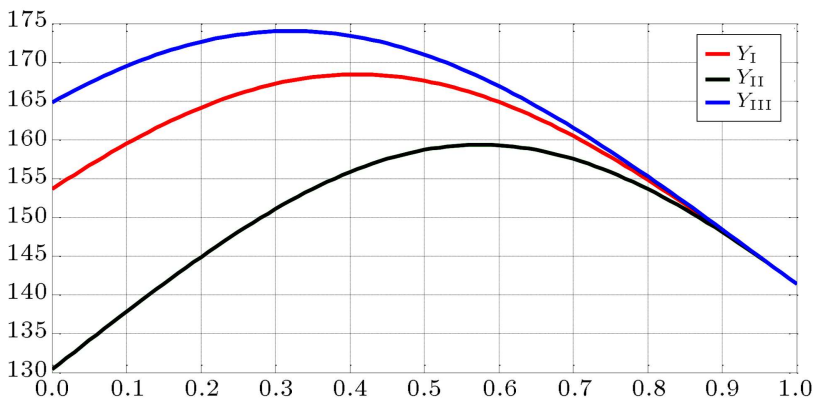

Figure 4. Behavior of raw material order size, $Y$, for each case for different values of imperfect rate, $q$.

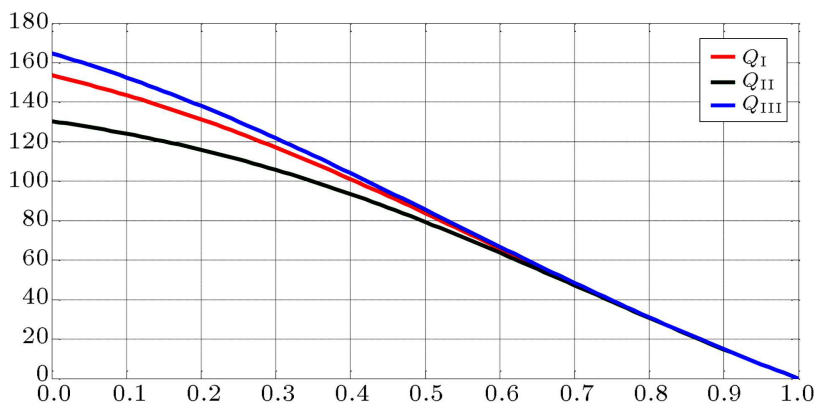

Figure 5. Behavior of finished product production size, $Q$, for each case for different values of imperfect rate, $q$.

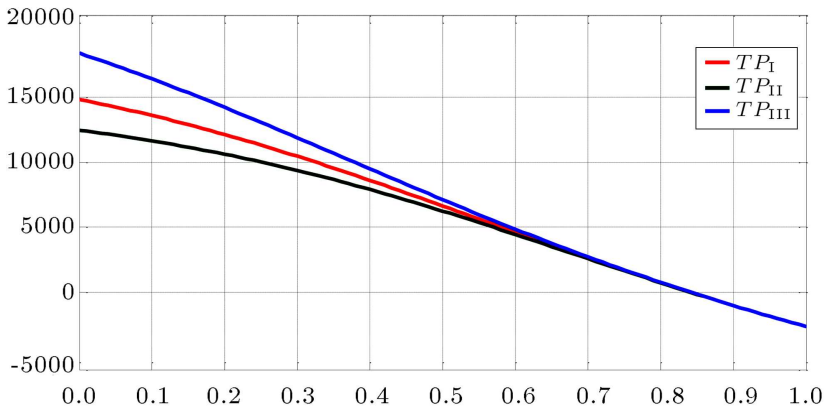

Figure 6. Behavior of total profit, $T P$, for each case for different values of raw material imperfect rate, $q$.

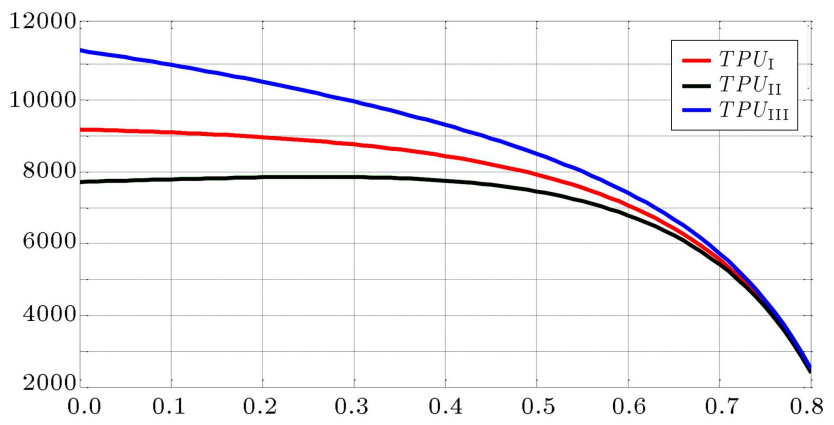

Figure 7. Behavior of total profit per unit time $T P U$ for each case for different values of raw material imperfect rate, $q$.

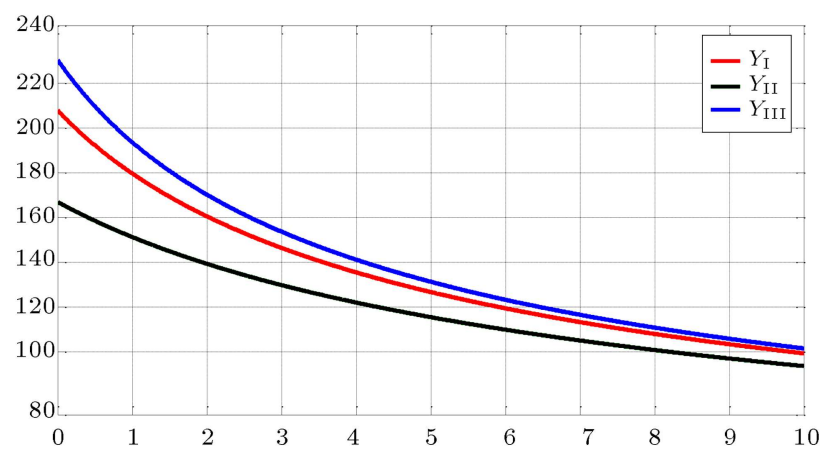

Figure 8. Behavior of raw material order size, $Y$, for each case for different values of holding cost of raw materials, $h_{1}$.

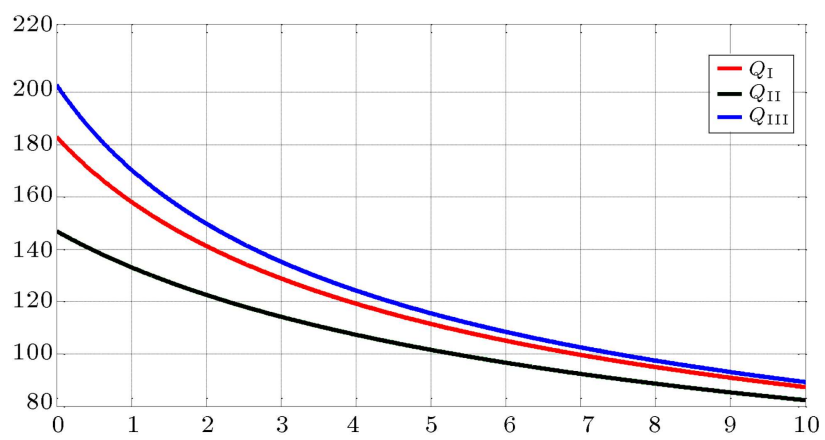

Figure 9. Behavior of finished product production size, $Q$ for each case for different values of holding cost of raw materials, $h_{1}$. 


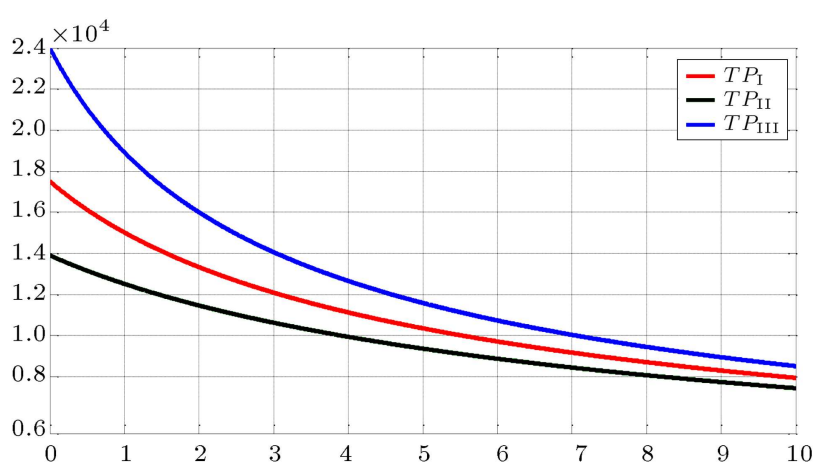

Figure 10. Behavior of total profit, $T P$, for each case for different values of holding cost of raw materials, $h_{1}$.

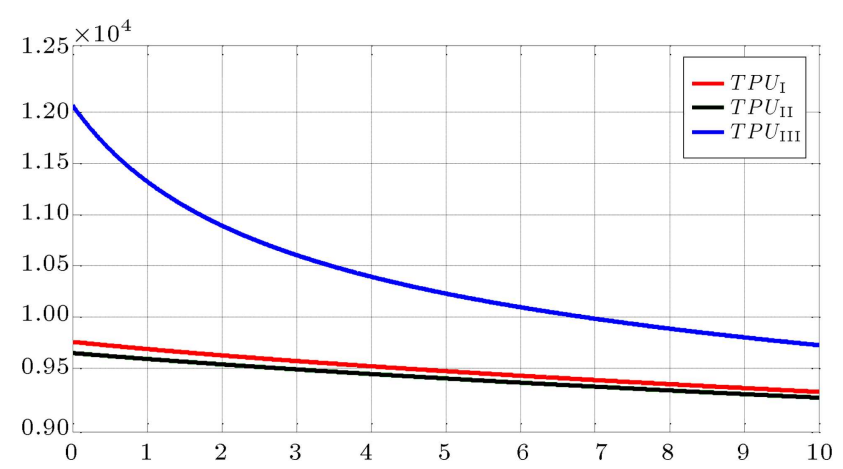

Figure 11. Behavior of total profit per unit time, $T P U$, for each case for different values of holding cost of raw materials, $h_{1}$.

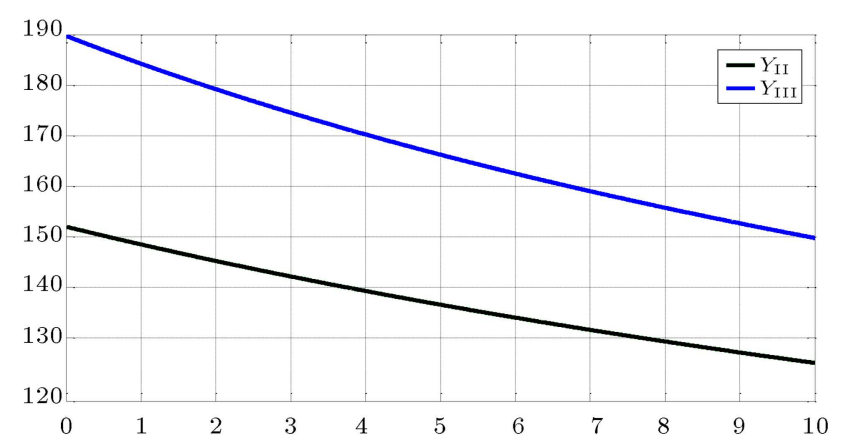

Figure 12. Behavior of raw material order size, $Y$, for each case for different values of shortage cost, $\pi$.

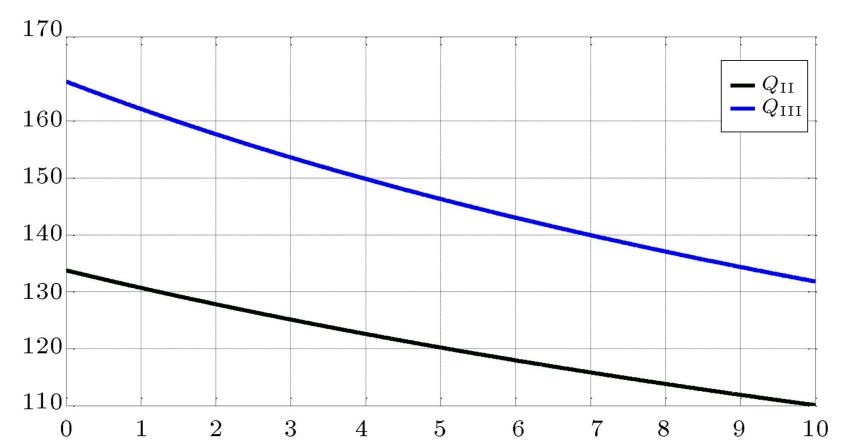

Figure 13. Behavior of finished product production size, $Q$, for each case for different values of shortage cost, $\pi$.

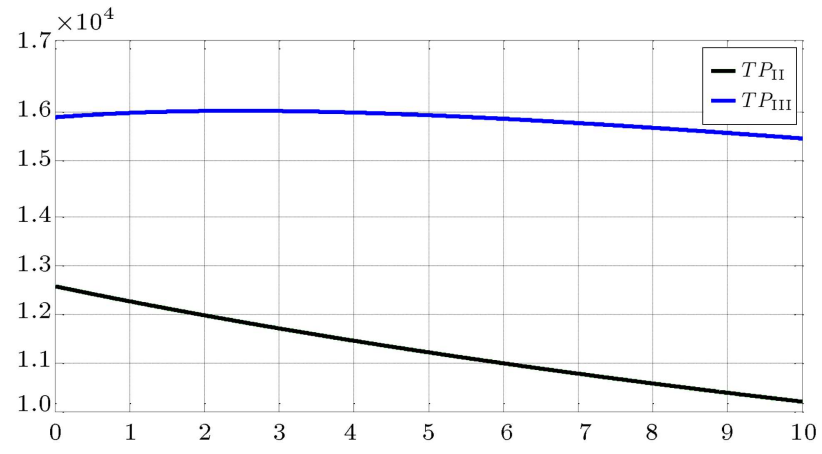

Figure 14. Behavior of total profit, $T P$, for each case for different values of shortage cost, $\pi$.

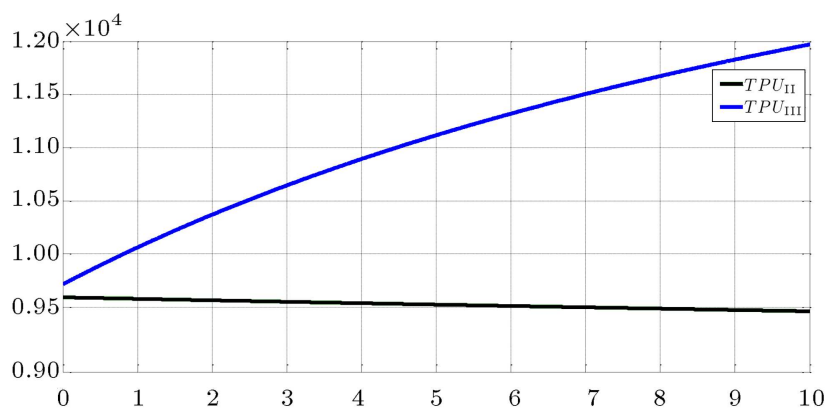

Figure 15. Behavior of total profit per unit time, TPU, for each case for different values of shortage cost, $\pi$.

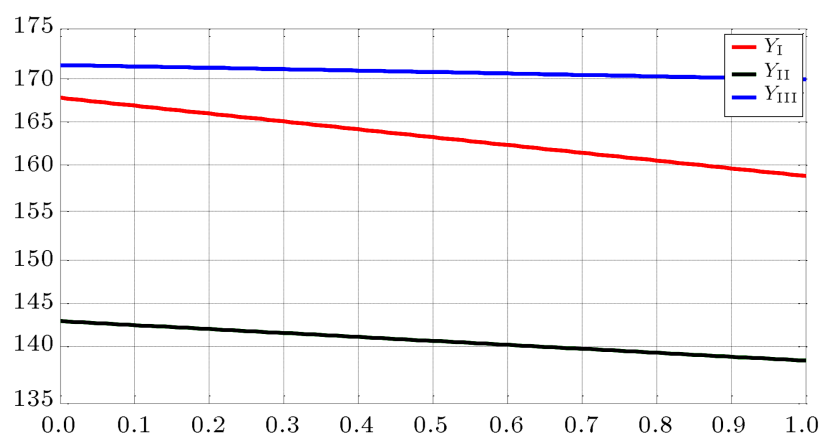

Figure 16. Behavior of raw material order size, $Y$, for each case for different values of percentage of reworkable items, $\alpha$.

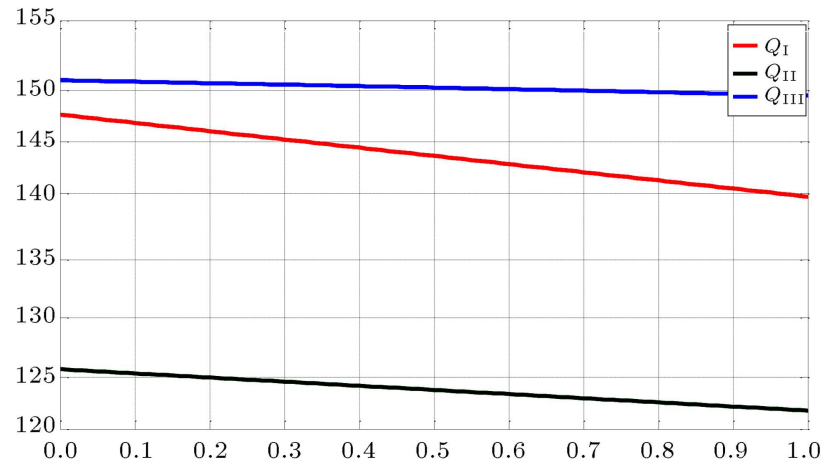

Figure 17. Behavior of finished product production size, $Q$, for each case for different values of percentage of reworkable items, $\alpha$. 
Table 2. Results of sensitivity analysis for Case I.

\begin{tabular}{cllll}
\hline Increase in & \multicolumn{3}{c}{ Impact on variables and objective functions } \\
\cline { 2 - 5 } parameter & \multicolumn{1}{c}{$\boldsymbol{Y}$} & \multicolumn{1}{c}{$\boldsymbol{Q}$} & \multicolumn{1}{c}{$\boldsymbol{T P}$} & \multicolumn{1}{c}{$\boldsymbol{P} \boldsymbol{U}$} \\
\hline$q$ & Increases and decreases & Decreases & Decreases & Decreases \\
$h_{1}$ & Decreases & Decreases & Decreases & Decreases \\
$\pi$ & Unchanged & Unchanged & Unchanged & Unchanged \\
$\alpha$ & Decreases & Decreases & Increases & Increases \\
\hline
\end{tabular}

Table 3. Results of sensitivity analysis for Case II.

\begin{tabular}{cllll}
\hline Increase in & \multicolumn{3}{c}{ Impact on variables and objective functions } \\
\cline { 2 - 5 } parameter & $\boldsymbol{Y}$ & $\boldsymbol{Q}$ & $\boldsymbol{T P}$ & $\boldsymbol{T P U}$ \\
\hline$q$ & Increases and decreases & Decreases & Decreases & Decreases \\
$h_{1}$ & Decreases & Decreases & Decreases & Decreases \\
$\pi$ & Decreases & Decreases & Decreases & Decreases \\
$\alpha$ & Decreases & Decreases & Increases & Increases \\
\hline
\end{tabular}

Table 4. Results of sensitivity analysis for Case III.

\begin{tabular}{cllll}
\hline Increase in & \multicolumn{3}{c}{ Impact on variables and objective functions } \\
\cline { 2 - 5 } parameter & \multicolumn{1}{c}{$\boldsymbol{Q}$} & $\boldsymbol{T P}$ & $\boldsymbol{T P U}$ \\
\hline$q$ & Increases and decreases & Decreases & Decreases & Decreases \\
$h_{1}$ & Decreases & Decreases & Decreases & Decreases \\
$\pi$ & Decreases & Decreases & Increases and decreases & Increases \\
$\alpha$ & Decreases & Decreases & Increases & Increases \\
\hline
\end{tabular}

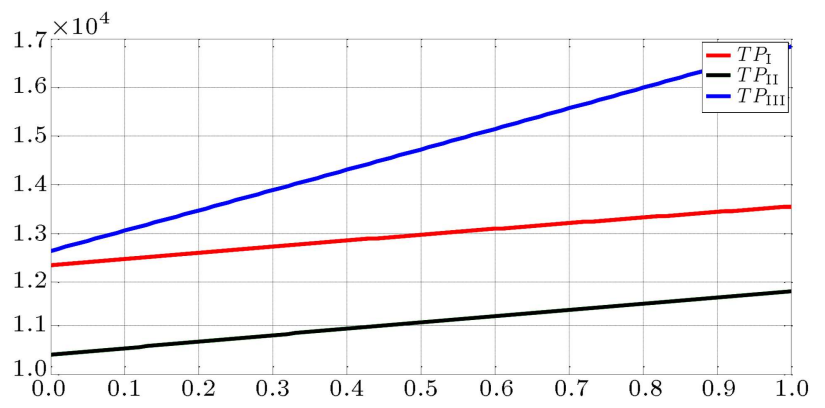

Figure 18. Behavior of total profit, $T P$, for each case for different values of percentage of reworkable items, $\alpha$.

order size, production size, and total profits do not change in this case. For this case, the raw material order size is fixed at $Y_{I}=160.5249$ (Figure 12), the finished product production size $Q_{I}$ is fixed at 141.2619 (Figure 13), the total profit $T P_{\mathrm{I}}$ is fixed at 13324.3934 (Figure 14), and the total profit per unit time $T P U_{\mathrm{I}}$ is fixed at 9624.9014. Moreover, the total profits in this case $\left(T P_{\mathrm{I}}\right.$ and $\left.T P U_{\mathrm{I}}\right)$ are less than those of Case III and greater than those of Case II. The total profit of the second case, $T P_{\mathrm{II}}$, starts from 12574.5545 and, then, decreases ultimately, while that of the third case, $T P_{\mathrm{III}}$, starts from 15894.0332, increases to 16029.0845, and then decreases. In addition, the total profit per unit of the second case, $T P U_{\mathrm{II}}$, starts from 9592.5027 and, then, decreases, while that of the third case, $T P U_{\mathrm{III}}$, starts from 9713.8521 and, then, increases. According

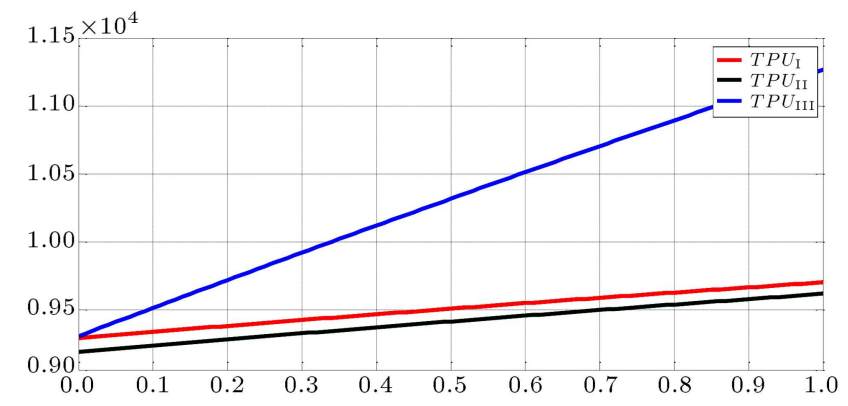

Figure 19. Behavior of total profit per unit time, $T P U$, for each case for different values of percentage of reworkable items, $\alpha$.

to Figures 16-19, it is clear that when the imperfect rate for raw materials percentage of reworkable items $\alpha$ increases, the total profit of the three cases exceeds the profit of each separate case. Generally, the third case is more beneficial among all the presented cases in terms of total profit and total profit per unit time.

\section{Conclusions}

In real-world manufacturing systems, there exist imperfect raw materials and defective products. In order to address these issues, this paper proposed a manufacturer system in which raw materials are supplied from an external source, and a finished product is produced. The structure of this manufacturing planning problem 
is based on an EPQ framework. The demand rate for an item is pre-known and constant; all order quantities are received instantaneously and all products are produced gradually via a finite production rate. Products are entirely consumed when the next order is commenced. No safety stock is allowed, there is no quantity discount, and ordering/setup cost is fixed per order/production. In addition to basic assumptions, the existence of a fraction of imperfect raw materials as well as a defective rate of production system is considered. A $100 \%$ screening process is carried out upon receiving raw materials, and imperfect items are sold at a discounted price. A number of defective products are reworkable and have the potential to become perfect after the reworking process, while others are scrapped items and sold at a lower price. The reworkable finished products go under a reworking process on the same machine. The defective rate is assumed to be a random variable, resulting in three possible cases regarding the occurrence of backordering shortage. Two scenarios for each case are designed, resulting in six total states. The concavity of total profit per unit times is derived for each case separately. Then, the optimal closed-form solution is derived for each case separately. The proposed manufacturing model is illustrated via a numerical example. An extensive sensitivity analysis is done to assess the impact of input changes on the outputs variations.

An interesting opportunity for future research is to adopt the proposed model for a more general situation where partial backordering shortage is permitted. Moreover, one may consider a sampling inspection instead of $100 \%$ inspection, the learning and forgetting effects in inspection, or quantity discount as future researches of this study.

\section{References}

1. Porteus, E. "Optimal lot sizing, process quality improvement and setup cost reduction", Oper. Res., 34(1), pp. 137-144 (1986).

2. Rosenblatt, M.J. and Lee, H.L. "Economic production cycles with imperfect production processes", IIE Trans., 18(1), pp. 48-55 (1986).

3. Salameh, M.K. and Jaber, M.Y. "Economic production quantity model for items with imperfect quality", Int. J. Prod. Econ., 64(1-3), pp. 59-64 (2000).

4. Cárdenas-Barrón, L. "Observation on: economic production quantity model for items with imperfect quality", Int. J. Prod. Econ., 67(2), p. 201 (2000).

5. Maddah, B. and Jaber, M.Y. "Economic order quantity for items with imperfect quality: revisited", Int. J. Prod. Econ., 112(2), pp. 808-815 (2008).

6. Rezaei, J. "Economic order quantity model with backorder for imperfect items", In Proceedings of IEEE international Engineering Management Conference,,
11-13 September. St. John's, Newfoundland, Canada, pp. 466-470 (2005).

7. Yu, J.C.P., Wee, H.M., and Chen, J.M. "Optimal ordering policy for a deteriorating item with imperfect quality and partial backordering", J. Chin. Inst. Ind. Eng., 22(6), pp. 509-520 (2005).

8. Wee, H.M., Yu, J.C.P., and Wang, K.J. "An integrated production-inventory model for deteriorating items with imperfect quality and shortage backordering considerations", Lect. Notes Comput. Sci. LNCS 3982, pp. 885-897 (2006).

9. Papachristos, S. and Konstantaras, I. "Economic ordering quantity models for items with imperfect quality", Int. J. Prod. Econ., 100(1), pp. 148-154 (2006).

10. Wee, H.M., Yu, J., and Chen, M.C. "Optimal inventory model for items with imperfect quality and shortage backordering", Omega, 35(1), pp. 7-11 (2007).

11. Khan, M., Jaber, M.Y., Guiffrida, A.L., and Zolfaghari, S. "A review of the extensions of a modified EOQ model for imperfect quality items", Int. J. Prod. Econ., 132(1), pp. 1-12 (2011).

12. Wahab, M.I.M., Mamun, S.M.H., and Ongkunaruk, P. "EOQ models for a coordinated two-level international supply chain", Int. J. Prod. Econ., 134(1), pp. 151-158 (2011).

13. Konstantaras, I., Skouri, K., and Jaber, M.Y. "Inventory models for imperfect quality items with shortages and learning in inspection", Appl. Math. Model., 36(11), pp. 5334-5343 (2012).

14. Liu, J. and Zheng, H. "Fuzzy economic order quantity model with imperfect items, shortages and inspection errors", Syst. Eng. Procedia, 4(1), pp. 282-289 (2012).

15. Hsu, J.T. and Hsu, L.F. "An EOQ model with imperfect quality items, inspection errors, shortage backordering, and sales returns", Int. J. Prod. Econ., 143(1), pp. 162-170 (2013).

16. Rad, M.A., Khoshalhan, F., and Glock, C.H. "Optimizing inventory and sales decisions in a two-stage supply chain with imperfect", Comput. Ind. Eng., 74(1), pp. 219-227 (2014).

17. Skouri, K., Konstantaras, I., Lagodimos, A.G., and Papachristos, S. "An EOQ model with backorders and rejection of defective supply batches", Int. J. Prod. Econ., 155(1), pp. 148-154 (2014).

18. Paul, S., Wahab, M.I.M., and Ongkunaruk, P. "Joint replenishment with imperfect items and price discount", Comput. Ind. Eng., 74(1), pp. 179-185 (2014).

19. Hlioui, A., Gharbi, A., and Hajji, A. "Replenishment, production and quality control strategies in three-stage supply chain", Int. J. Prod. Econ., 166(1), pp. 90-102 (2015).

20. Sharifi, E., Sobhanallahi, M.A., and Mirzazadeh, A. "An EOQ model for imperfect quality items with partial backordering under screening errors", Cogent Eng., 2(1), Article: 994258 (2015). 
21. Alamri, A.A., Harris, I., and Syntetos, A.A. "Efficient inventory control for imperfect quality items", Eur. J. Oper. Res., 254(1), pp. 92-104 (2016).

22. Chang, C.T., Cheng, M.C., and Soong, P.Y. "Impacts of inspection errors and trade credits on the economic order quantity model for items with imperfect quality", Int. J. Syst. Sci.: Oper. Logist., 3(1), pp. 34-48 2016.

23. Rezaei, J. "Economic order quantity and sampling inspection plans for imperfect items", Comput. Ind. Eng., 96(1), pp. 1-7 (2016).

24. Yu, H.F., and Hsu, W.K. "An integrated inventory model with immediate return for defective items under unequal-sized shipments", J. Ind. Prod. Eng., 34(1) pp. 70-77 (2017).

25. Sarkar, B. and Saren, S. "Product inspection policy for an imperfect production system with inspection errors and warranty cost", Eur. J. Oper. Res., 248(1), pp. 263-271 (2016).

26. Ongkunaruk, P., Wahab, M.I.M., and Chenc, Y. "A genetic algorithm for a joint replenishment problem with resource and shipment constraints and defective items", Int. J. Prod. Econ.m 175(1), pp. 142-152 (2016).

27. Taleizadeh, A., Lashgari, M., Akram, R., and Heydari, J. "Imperfect economic production quantity model with upstream trade credit periods linked to raw material order quantity and downstream trade credit periods", Appl. Math. Model., 40(19-20), pp. 87778793 (2016).

28. Cheikhrouhou, N., Sarkar, B., Ganguly, B., Malik, A.I., Batista, R., and Lee, Y.H. "Optimization of sample size and order size in an inventory model with quality inspection and return of defective items", Annals of Operations Research, pp. 1-23 (2017) (In Press).

29. Taleizadeh, A.A., and Zamani Dehkordi, N. "Economic order quantity with partial backordering and sampling inspection", J. of Ind. Eng. Inter., 13(3), pp. 331-345 (2017).

30. Mokhtari, H. and Rezvan, M.T. "A single-supplier, multi-buyer, multi-product VMI production-inventory system under partial backordering", Operational Research, pp. 1-21 (2017) (In Press).
31. Jaber, M.Y., Zanoni, S., and Zavanella, L.E. "Economic order quantity models for imperfect items with buy and repair options", Int. J. Prod. Econ., 155(1), pp. 126-131 (2014).

32. Chiu, S.W., Chou, C.L., and Wu, W.K. "Optimizing replenishment policy in an EPQ based inventory model with nonconforming items and breakdown", Econ. Model., 35(1), pp. 330-337 (2013).

33. Bouslah, B., Gharbi, A., and Pellerin, R. "Joint optimal lot sizing and production control policy in an unreliable and imperfect manufacturing system", Int. J. Prod. Econ., 144(1), pp. 143-156 (2013).

34. Mokhtari, H., Naimi-Sadigh, A., and Salmasnia, A. "A computational approach to economic production quantity model for perishable products with backordering shortage and stock-dependent demand", Scientia Iranica, 24(4), pp. 2138-2151 (2017).

35. Tayyab, M., and Sarkar, B. "Optimal batch quantity in a cleaner multi-stage lean production system with random defective rate", J. of Cleaner Prod., 139(1), pp. 922-934 (2016).

36. Mokhtari, H. "A joint internal production and external supplier order lot size optimization under defective manufacturing and rework", The International Journal of Advanced Manufacturing Technology, 95(1-4), pp. 1039-1058 (2018).

\section{Biography}

Hadi Mokhtari is currently an Assistant Professor of Industrial Engineering in University of Kashan, Iran. His current research interests include the application of operations research and artificial intelligence techniques to the areas of project scheduling, production scheduling, and manufacturing supply chains. He also published several papers in international journals such as Computers and Operations Research, International Journal of Production Research, Applied Soft Computing, Neurocomputing, International Journal of Advanced Manufacturing Technology, IEEE Transactions on Engineering Management, and Expert Systems with Applications. 